Title: Alterations of apparent diffusion coefficient (ADC) in the brain of rats chronically exposed to lead acetate.

Article Type: Regular Article

Keywords: KEY WORDS: lead neurotoxicity, vasogenic oedema, blood-brain barrier, reticular formation, apparent diffusion coefficient, magnetic resonance imaging

Corresponding Author: Dr. Omar Cauli, PhD

Corresponding Author's Institution: Centro de Investigación Príncipe Felipe

First Author: Pilar López-Larrubia

Order of Authors: Pilar López-Larrubia; Omar Cauli, PhD

Abstract: ABSTRACT

Diffusion-weighted imaging (DWI) allows the assessment of the water apparent diffusion coefficient (ADC), a measure of tissue water diffusivity which is altered during different pathological conditions such as cerebral oedema. By means of DWI, we repeatedly measured in the same rats apparent diffusion coefficient ADC in different brain areas (motor cortex (MCx), somato-sensory cortex (SCx), caudate-putamen $(\mathrm{CPu})$, hippocampus (Hip), mesencephalic reticular formation (RF), corpus callosum (CC) and cerebellum (Cb)) after 1 week, 4 and 12 weeks of lead acetate exposure via drinking water ( 50 or $500 \mathrm{ppm}$ ). After 12 weeks of lead exposure rats received albumin-Evans blue complex administration and were sacrified one hour later. Blood-brain barrier permeability and water tissue content were determined in order to evaluate their relationship with ADC changes. Chronic exposure to lead acetate (500 ppm) for 4 weeks increased ADC values in Hip, RF and $\mathrm{Cb}$ but no in other brain areas. After 12 weeks of lead acetate exposure at 500 ppm ADC is significantly increased also in CPu and CC. Brain areas displaying high ADC values after lead exposure showed also an increased water content and increased BBB permeability to Evans blue-albumin complex. Exposure to $50 \mathrm{ppm}$ for 12 weeks increased ADC values and BBB permeability in the RF and Cb. In summary, chronic lead exposure induces cerebral oedema in the adult brain depending on the brain area and the dose of exposure. $\mathrm{RF}$ and $\mathrm{Cb}$ appeared the most sensitive brain areas whereas cerebral cortex appears resistant to lead-induced cerebral oedema. 


\title{
Alterations of apparent diffusion coefficient (ADC) in the brain of rats chronically exposed to lead acetate.
}

\author{
Pilar López-Larrubia ${ }^{1}$ and Omar Cauli $^{2}$ \\ ${ }^{1}$ Laboratory for Imaging and Spectroscopy by Magnetic Resonance LISMAR, Instituto de \\ Investigaciones Biomédicas "Alberto Sols" C.S.I.C./UAM, Madrid, Spain \\ ${ }^{2}$ Laboratory of Neurobiology, Centro de Investigación Príncipe Felipe, Valencia, Spain
}

\author{
Correspondence should be sent to: Dr. Omar Cauli, Laboratory of Neurobiology, Centro \\ de Investigación Príncipe Felipe. Avda Autopista del Saler, 16, 46013 Valencia. \\ e-mail: omar.cauli@cipf.es \\ Tel: $34963289680 \quad$ Fax: 34963289701
}

\begin{abstract}
ABBREVIATIONS:
ADC, apparent diffusion coefficient; BBB, blood-brain barrier; MRI, Magnetic resonance imaging; DWI, Diffusion-weighted imaging, $\mathrm{MCx}$, motor cortex; SCx, somato-sensory cortex; Hip, hippocampus; RF, reticular formation; $\mathrm{CC}$, corpus callosum; $\mathrm{CPu}$, caudateputamen; $\mathrm{Cb}$, cerebellum.
\end{abstract}




\begin{abstract}
Diffusion-weighted imaging (DWI) allows the assessment of the water apparent diffusion coefficient (ADC), a measure of tissue water diffusivity which is altered during different pathological conditions such as cerebral oedema. By means of DWI, we repeatedly measured in the same rats apparent diffusion coefficient ADC in different brain areas (motor cortex $(\mathrm{MCx})$, somato-sensory cortex $(\mathrm{SCx})$, caudate-putamen $(\mathrm{CPu})$, hippocampus (Hip), mesencephalic reticular formation (RF), corpus callosum (CC) and cerebellum (Cb)) after 1 week, 4 and 12 weeks of lead acetate exposure via drinking water (50 or 500 ppm). After 12 weeks of lead exposure rats received albumin-Evans blue complex administration and were sacrified one hour later. Blood-brain barrier permeability and water tissue content were determined in order to evaluate their relationship with ADC changes. Chronic exposure to lead acetate (500 ppm) for 4 weeks increased ADC values in Hip, RF and $\mathrm{Cb}$ but no in other brain areas. After 12 weeks of lead acetate exposure at 500 ppm ADC is significantly increased also in $\mathrm{CPu}$ and $\mathrm{CC}$. Brain areas displaying high ADC values after lead exposure showed also an increased water content and increased BBB permeability to Evans blue-albumin complex. Exposure to 50 ppm for 12 weeks increased ADC values and BBB permeability in the RF and $\mathrm{Cb}$. In summary, chronic lead exposure induces cerebral oedema in the adult brain depending on the brain area and the dose of exposure. $\mathrm{RF}$ and $\mathrm{Cb}$ appeared the most sensitive brain areas whereas cerebral cortex appears resistant to leadinduced cerebral oedema.
\end{abstract}

KEY WORDS: lead neurotoxicity, vasogenic oedema, blood-brain barrier, reticular formation, apparent diffusion coefficient, magnetic resonance imaging 


\section{Introduction}

Lead $(\mathrm{Pb})$ neurotoxicity is still a major medical concern in both environmental and occupational settings (CDC 2000). The clinical effects of acute and chronic lead toxicity are well documented (Davis et al. 1993, Grandjean 1993). Acute lead intoxication induces oedema in the brain of humans and laboratory animals (Goldstein et al., 1974; Holtzman et al., 1982; Hossain et al., 2004; Lögdberg et al., 1988; Pentschew, 1965; Villeda-Hernández et al., 2006; Winder et al., 1983; Winder 1984 for review). Two main types of cerebral oedema have been described, namely, vasogenic and cytotoxic oedema. Vasogenic oedema can be induced when water entries into the brain following an alteration of blood-brain barrier (BBB) permeability thus leading to an accumulation of water in the extracellular space (Klatzo 1967). In cytotoxic oedema (also called cellular oedema), water accumulation occurs inside the cells mainly in astrocytes (Klatzo 1967).

It has been reported that acute lead intoxication in children and perinatal lead exposure in young animals cause cerebral oedema, in particular, vasogenic oedema (Hossain et al., 2004; Lefauconnier et al., 1983;Villeda-Hernández et al., 2006). Cytotoxic oedema has also been reported in one study (Lefauconnier et al., 1983). Different brain areas display different vulnerability to lead-induced cerebral oedema in young animals. Lead exposure (160 or $320 \mathrm{ppm}$ in the drinking water) from gestational day 1 to gestational day 21 dosedependently induce interstitial/vasogenic oedema in different brain regions of rat fetuses such as parietal cortex, striatum, thalamus and cerebellum (Villeda-Hernandez et al., 2006) while Hossain et al. (2004) reported that cerebellum is the more susceptible brain region to lead-induced oedema in newborn rats. One of the events that contribute to vasogenic 
oedema formation in the brain is the increase of BBB permeability.

Vasogenic oedema resulting from BBB failure causes transvascular leak of blood proteins (albumin, fibrinogen, fibronectin and immunoglobulins) with concurrent oncotic influx of water and failure of compensatory mechanisms of fluid homeostasis. According to the proposed link between alteration of $\mathrm{BBB}$ permeability and the occurrence of vasogenic oedema, it has been shown in young animals that lead exposure impairs BBB permeability (Hossain et al., 2004; Sundstrom and Kalimo 1987; Sundstrom et al., 1985; Wang et al., 2007).

Moreover, several reports have demonstrated that lead accumulates not only in BBB endothelial cells (Struzynska et al., 1997; Toews et al., 1978) but also in the choroid plexus (Friedheim et al., 1983; Manton et al., 1984; Zheng et al., 1991) where it increases the leakage of the blood-cerebrospinal fluid barrier (Shi and Zheng 2007). These findings suggest that the mechanisms involved in brain water homeostasis might be altered during lead exposure.

Magnetic resonance imaging (MRI) is a non invasive tool that provides information about changes in cerebral function in brain in vivo. MRI is the ideal modality to characterize the temporal and spatial evolutions of neuropathologies in vivo. Among different parameters that could be analyzed by MRI, diffusion weighted imaging (DWI) allows to calculate the apparent diffusion coefficient (ADC), which is altered in brain edema. ADC value reflects water mobility (expressed as $\mu \mathrm{m}^{2} / \mathrm{sec}$ ) in the tissue. Changes in ADC can reflect the presence of cerebral oedema (Rovira et al. 2002; Schaefer 2000) that, in turn, can be vasogenic or cytotoxic. Cytotoxic oedema is accompanied by a decrease of ADC value (Schaefer et al. 2000) while vasogenic oedema is accompanied by an increase of ADC 
value (McManus et al. 1995). In cytotoxic oedema ADC value decreases because water goes inside the cells where it cannot move as quickly as it can in the extracellular space. In vasogenic oedema, water content increases in the extracellular space leading to an increase of ADC value. Although children and youngest animals are more susceptible to leadinduced brain oedema (Holtzman et al., 1982; Winder 1984) it has also been reported in the adult brain following acute or subacute lead exposure (Atre et al., 2006; Rojas-Marcos I et al., 2002; Saryan and Zenz 1994). To our knowledge, no studies have been performed yet to address whether chronic lead exposure elicits brain oedema in the adult brain and if different brain areas present different susceptibility to this effect.

In this work we assessed:

1) whether chronic lead exposure $(0,50,500 \mathrm{ppm})$ in adults rats modifies ADC in different brain areas (motor cortex (MCx), somatosensory cortex (SCx), caudateputamen $(\mathrm{CPu})$, hippocampus (Hip), mesencephalic reticular formation $(\mathrm{RF})$, corpus callosum (CC) and cerebellum(Cb)).

2) the time-course of these changes by measuring ADC in the same subjects at different time points during lead exposure (1, 4 and 12 weeks).

3) If $\mathrm{ADC}$ alterations are accompanied by alterations of $\mathrm{BBB}$ permeability and water content.

Water content was measured by wet-dry method and BBB permeability by Evans-blue extravasation method which has been extensively used to study BBB permeability (Hawkins and Davis 2005 for review). 


\section{MATERIALS AND METHODS}

Male Wistar rats (250-300 g) were used. Rats were given food and water ad libitum and kept in the air-conditioned experimental room at $21-23{ }^{\circ} \mathrm{C}$ with a $12: 12 \mathrm{~h}$ light-dark cycle. Rats were divided into 3 groups: control rats drinking distillated water containing sodium acetate 50 or $500 \mathrm{ppm}(\mathrm{N}=3$ each); lead acetate $50 \mathrm{ppm}$ dissolved in the drinking water $(\mathrm{N}=6)$; lead acetate $500 \mathrm{ppm}$ dissolved in the drinking water $(\mathrm{N}=6)$. New solutions of lead acetate were prepared daily and acidified with chloridric acid (final $\mathrm{pH}$ 7) to avoid precipitation. The animal experiments were approved by the Center and met the guidelines of the European Community for care and management of experimental animals. Body weights were measured once per week and fluid intake every three days. After 12 weeks of lead exposure rats were injected with Evans blue (see below) and sacrificed one hour later. With the help of coronal slicer matrix (1 mm thickness slices) we isolated $\mathrm{MCx}, \mathrm{SCx}$, Hip, $\mathrm{CPu}$, half of the $\mathrm{Cb}$ (cut along the vermis), half of $\mathrm{CC}$ (cut perpendicular to the coronal plane), half of the mesenchephalic RF (cut coronally at the level of the fourth ventricle) from one hemisphere to measure the concentration of Evans blue and lead while the other brain areas belonging to the other hemisphere were used for water determination. Since the amount of tissue of $\mathrm{CC}$ is low, prior tissue processing, $3 \mathrm{CC}$ belonging to 3 different rats of the same experimental group were pooled together to measure Evans blue and lead. CC of remaining 3 rats were pooled together to determine water content. Data from control rats exposed to 50 or $500 \mathrm{ppm}$ of sodium acetate produced similar results in each of the measurements performed in the study so the data were pooled together.

\section{Magnetic Resonance Imaging (MRI) experiments}

MRI experiments were performed on a Bruker Pharmascan system (Bruker Medical Gmbh, 
Ettlingen, Germany) using a 7.0-T horizontal-bore superconducting magnet, equipped with a ${ }^{1} \mathrm{H}$ selective birdcage resonator of $38 \mathrm{~mm}$ and a Bruker gradient insert with $90 \mathrm{~mm}$ of diameter (maximum intensity $36 \mathrm{G} / \mathrm{cm}$ ). All data were acquired using a Hewlett-Packard console running Paravision software (Bruker Medical Gmbh, Ettlingen, Germany) operating on a Linux platform. Anesthesia was initiated by inhalation of oxygen (1 1/min) containing $4 \%$ isofluorane and maintained during the experiment employing a mask and 2 $\%$ isofluorane in $\mathrm{O}_{2}$. Animal temperature was maintained at approx. $37^{\circ} \mathrm{C}$ with a heated probe. The physiological state of the rats was monitored using a Biotrig physiological monitor (Bruker, Germany) that controlled the respiratory rate and body temperature.

\section{Apparent diffusion coefficient (ADC) mapping}

Diffusion-weighted imaging (DWI) measures the relative translational motion of water molecules across cell membrane, which is expressed as the apparent diffusion coefficient (ADC) value.

The ADC maps were obtained based in diffusion weighted images and the following parameters: $\mathrm{TR}=2500 \mathrm{~ms}, \mathrm{TE}=25 \mathrm{~ms}, \mathrm{Av}=1$, diffusion gradient duration $=4 \mathrm{~ms}$, diffusion gradient separation $=16 \mathrm{~ms}$, acquisition matrix $=128 \times 128$ corresponding to an in-plane resolution of $312 \times 312 \mu \mathrm{m}^{2}$, b factors $=100,400$ and $1000 \mathrm{~s} / \mathrm{mm}^{2}$. Maps were obtained by a linear fitting of the logarithm of signal intensity (S) versus the $b$ factor according to the expression:

$$
\mathrm{S}_{\mathrm{b}}=\mathrm{S}_{0} \exp (-\mathrm{ADC} \times \mathrm{b})
$$

MRI signal intensity was analysed in the brain areas of interest by ADC values $\left(\mu \mathrm{m}^{2} / \mathrm{sec}\right)$ in the corresponding maps, after capturing images with Image $\mathbf{J}$ which calculates the mean value for all pixels contained in the selected brain region. The different brain regions were 
identified according to the stereotaxic coordinates of the rat brain atlas and to online plates of the atlas (Paxinos and Watson 1996). The regions analysed were MCx, SCx, CPu, Hip, $\mathrm{RF}, \mathrm{CC}$ and $\mathrm{Cb}$. ADC measurements were performed in the same subjects at different time points (1, 4 and 12 weeks) in order to perform a longitudinal study.

\section{Measurement of blood-brain barrier permeability}

BBB permeability was quantitatively evaluated by measuring the amount of extravasated Evans blue dye in the tissue at 12 weeks of chronic lead exposure according to procedure described in Hawkins and Egleton (2006). Evan's blue (2\%, containing 18 g/l bovine serum albumin $4 \mathrm{~mL} / \mathrm{kg}$ ) was injected over 2 min into the left femoral vein; it was allowed to circulate for $60 \mathrm{~min}$. After decapitation, the brain was removed and $\mathrm{MCx}, \mathrm{SCx}, \mathrm{CPu}, \mathrm{Hip}$, $\mathrm{RF}, \mathrm{CC}$ and $\mathrm{Cb}$ were isolated. Brains areas were weighted and homogenized in five-fold volume of $50 \%$ trichloroacetic acid solution. The supernatant was obtained by centrifugation $\left(10 \mathrm{~min}, 10,000 \times g\right.$, at $\left.4{ }^{\circ} \mathrm{C}\right)$. Evans blue extravasation was quantified in the supernatants by measuring the fluorescence (excitation at $620 \mathrm{~nm}$ and emission at $680 \mathrm{~nm}$ ) (Abraham et al., 1996). The amount of extravasated Evans blue dye was expressed as nanogram per gram of brain tissue.

\section{Evaluation of brain oedema}

Wet-dry weight determinations (a simple and sensitive assay to measure brain oedema) of control and lead acetate-exposed brains were performed 12 weeks after chronic lead exposure. $\mathrm{MCx}, \mathrm{SCx}, \mathrm{CPu}$, Hip, $\mathrm{RF}, \mathrm{CC}$ and $\mathrm{Cb}$ were quickly dissected and the initial weight of each sample (wet weight) was determined. Samples then were dried in an oven at $110^{\circ} \mathrm{C}$ for 24 hours, and the respective dry weight for each specimen was obtained. Tissue water content was calculated as [(wet weight - dry weight)/wet weight $] \times 100 \%$ (Abe et 
al.1988).

\section{Lead measurement}

The day after the last MRI scanning, rats were anesthetized with isoflurane, rapidly decapitated, blood was collected from the neck and brain areas ( $\mathrm{MCx}, \mathrm{SCx}, \mathrm{CPu}, \mathrm{Hip}, \mathrm{RF}$, $\mathrm{CC}$ and $\mathrm{Cb}$ ) were immediately dissected, frozen on liquid nitrogen, and stored at $-80{ }^{\circ} \mathrm{C}$ until analysis of lead content. Lead content in brains and blood was analyzed by the Inductive Coupled Plasma-Atomic Emission Spectrometry (ICPAES). Brain tissue (20-40 mg) was first processed by wet digestion (20\% nitric acid and microwave exposure). The detection level of the method was $1.5 \mu \mathrm{g} / \mathrm{kg}$ wet-weight. For blood lead analysis, an aliquot of blood $(100 \mu \mathrm{l})$ were first diluted ten times with $0.1 \%$ triton X-100/nitric acid.

\section{Statistical analysis}

The results are presented as mean \pm standard error of mean (S.E.M.). The data were analyzed by one-way ANOVA followed Dunnett T-test or two-way ANOVA followed Bonferroni post-hoc test. $p$ values lower than 0.05 were considered statistically significant. Statistical analysis was performed using the Graph Pad Prism 5 software (GraphPad Software Inc. San Diego, CA, USA).

\section{RESULTS}

\section{Body weight, daily $\mathrm{Pb}$ fluid intake.}

No statistically differences in the gain of body weight of rats among the experimental

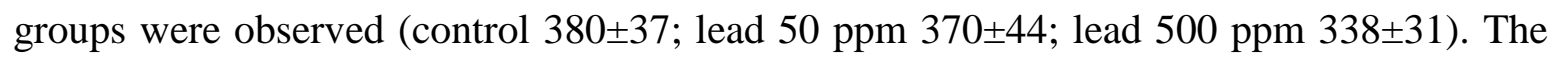
average daily intake of lead was 4.2 and $44 \mathrm{mg} \mathrm{Pb} / \mathrm{kg} /$ day for the group drinking water containing 50 and 500 ppm, respectively. No significant differences of fluid intake were observed among experimental groups. $\mathrm{Pb}$ intake in the control group (sodium acetate in the 
drinking water) was below the limit detection.

\section{Apparent diffusion coefficient}

$A D C$ values after one week of lead exposure

2-way analysis of variance of ADC values after one week of lead acetate exposure (50 or $500 \mathrm{ppm})$ shows no significant effect of dose $(\mathrm{F}(2,105)=0.097 ; \mathrm{p}=0.9903)$, a significant effect of the brain region $(\mathrm{F}(6,105)=140.6$; $\mathrm{p}<0.0001)$ and no significant dose $\mathrm{X}$ brain region interaction $(\mathrm{F}(12,105)=0.5524 ; \mathrm{p}=0.8750)$. The significant effect of brain region was due the lowest values of $\mathrm{ADC}$ in $\mathrm{CC}(\mathrm{p}<0.001)$, a pure white matter region. Each value is the mean of $\mathrm{N}=6$ rats. (Table 1 ).

$A D C$ values after four weeks of lead exposure

2-way analysis of variance of ADC values after four weeks of lead acetate exposure (50 or $500 \mathrm{ppm})$ shows a significant effect of dose $(\mathrm{F}(2,105)=6.70 ; \mathrm{P}<0.0018)$, a significant effect of the brain region $(\mathrm{F}(6,105)=167 ; \mathrm{p}<0.0001)$ and a significant dose $\mathrm{X}$ brain region interaction $(\mathrm{F}(12,105)=2.32 ; \mathrm{p}<0.0113)$. Bonferroni post-hoc test shows that exposure to lead acetate $500 \mathrm{ppm}$ in the drinking water significantly increased ADC value in Hip, RF and $\mathrm{Cb}(\mathrm{p}<0.05, \mathrm{p}<0.01, \mathrm{p}<0.05$ respectively) as compared to the ADC value of Hip, RF and $\mathrm{Cb}$ in the vehicle group. ADC values of $\mathrm{CC}$ were significantly lower as compared to ADC values of other brain regions but lead exposure did not significantly modify ADC value in CC. Exposure to $50 \mathrm{ppm}$ lead acetate did not produce any significant change of ADC values in any of the brain region examined (Table 2). Each value is the mean of $\mathrm{N}=6$ rats. 
$A D C$ values after twelve weeks of lead exposure

2-way analysis of variance of ADC values after twelve weeks of lead acetate exposure (50 or $500 \mathrm{ppm})$ shows a significant effect of dose $(\mathrm{F}(2,105=19.63 ; \mathrm{P}<0.0001)$, a significant effect of the brain region $(F(8,105)=170.2 ; \mathrm{p}<0.0001)$ and a significant dose $\mathrm{X}$ brain region interaction $(\mathrm{F}(12,105)=2.45 ; \mathrm{p}=0.0074)$. Bonferroni post-hoc test shows that exposure to lead acetate $50 \mathrm{ppm}$ in the drinking water significantly increased ADC value in $\mathrm{RF}(\mathrm{p}<0.05)$ and in $\mathrm{Cb}(\mathrm{p}<0.05)$ as compared to the $\mathrm{ADC}$ value of $\mathrm{RF}$ and of $\mathrm{Cb}$ in the vehicle group. Bonferroni post-hoc test shows that exposure to lead acetate $500 \mathrm{ppm}$ in the drinking water significantly increased $\mathrm{ADC}$ value in $\mathrm{CPu}(\mathrm{p}<0.01)$, Hip $(\mathrm{p}<0.05), \mathrm{RF}$ ( $\mathrm{p}<0.01), \mathrm{CC}(\mathrm{p}<0.05)$ and $\mathrm{Cb}(\mathrm{p}<0.05)$ as compared to ADC values in the corresponding brain areas in the vehicle group. Moreover Bonferroni post-hoc test shows significant differences between $\mathrm{ADC}$ values of Hip, $\mathrm{CPu}$ and $\mathrm{CC}$ in rats exposed to $500 \mathrm{ppm}$ lead acetate compared to $\mathrm{ADC}$ values of $\mathrm{Hip}, \mathrm{CPu}$ and $\mathrm{CC}$ of rats exposed to $50 \mathrm{ppm} \quad(\mathrm{p}<0.05$ for Hip and $\mathrm{CC}$ and $\mathrm{p}<0.01$ for $\mathrm{CPu}$ ). Each value is the mean of $\mathrm{N}=6$ rats. (Table 3). Representative MRI scans showing ADC changes are reported in Figure 1.

\section{Determination of water content.}

In order to assess whether changes in ADC induced by lead exposure reflect the presence of cerebral oedema we determined water content (expressed as percentage of water in brain tissue) 12 weeks after lead acetate exposure (50 or $500 \mathrm{ppm}$ in the drinking water) in the same brain areas analyzed by MRI (Figure 2). 2-way analysis of variance of water content data shows a significant effect of dose $(F(2,93=13.94 ; \mathrm{p}<0.0001)$, a significant effect of the brain region $(\mathrm{F}(6,93)=3.03 ; \mathrm{p}<0.01)$ and a no significant dose $\mathrm{X}$ brain region interaction $(\mathrm{F}(12,93)=1.69 ; \mathrm{p}=0.08)$. Bonferroni post-hoc test shows that exposure to lead 
acetate at $500 \mathrm{ppm}$ in the drinking water significantly increased water content in $\mathrm{CPu}$ $(\mathrm{p}<0.05)$, Hip $(\mathrm{p}<0.01), \mathrm{RF}(\mathrm{p}<0.05), \mathrm{CC}(\mathrm{p}<0.01)$ and in $\mathrm{Cb}(\mathrm{p}<0.05)$ compared to water content in the corresponding brain areas in control rats. No significant differences were observed between water content in the group exposed to $50 \mathrm{ppm}$ lead acetate compared to vehicle group (Figure 2).

\section{Blood Brain Barrier permeability.}

In order to evaluate if ADC changes induced by chronic lead acetate (50 or $500 \mathrm{ppm}$ in the drinking water) were accompanied by alteration of BBB permeability we injected the fluorescent dye one hour before sacrifying the rats after 12 weeks of lead exposure. Evans blue was determined in the 7 brain areas and results expressed as $\mu \mathrm{g}$ of Evans blue/g tissue (Figure 3). 2-way analysis of variance of BBB permeability data shows a significant effect of dose $(F(2,93=39.44 ; p<0.0001)$, a significant effect of the brain region $(F(6,93)=6.21$; $\mathrm{p}<0.0001)$ and a significant dose $X$ brain region interaction $(F(12,93)=2.65 ; p=0.004)$. Bonferroni post-hoc test shows that exposure to lead acetate at $50 \mathrm{ppm}$ in the drinking water significantly increased BBB permeability in the RF $(\mathrm{p}<0.05)$, and in $\mathrm{Cb}(\mathrm{p}<0.05)$ compared to values of $\mathrm{RF}$ and $\mathrm{Cb}$ in control rats.

Bonferroni post-hoc test shows that exposure to $500 \mathrm{ppm}$ lead acetate in the drinking water significantly increased BBB permeability in $\mathrm{CPu}(\mathrm{p}<0.001), \operatorname{Hip}(\mathrm{p}<0.05), \mathrm{RF}(\mathrm{p}<0.01)$, $\mathrm{CC}(\mathrm{p}<0.05)$ and in $\mathrm{Cb}(\mathrm{p}<0.001)$ compared to the corresponding values in control rats.

\section{Lead levels in blood and in brain areas}

In order to assess whether results obtained for $\mathrm{ADC}$ values, water content and $\mathrm{BBB}$ permeability in different brain areas (MCx, SCx, $\mathrm{CPu}, \mathrm{Hip}, \mathrm{RF}, \mathrm{CC}$ and $\mathrm{Cb}$ ) were due to different lead concentrations, we analyzed lead content in each brain area (expressed as 
$\mu \mathrm{g} / \mathrm{g}$ tissue) (Figure 4). Two-way analysis of variance shows a significant effect of dose (F $(2,93)=368.9 ; \mathrm{p}<0.0001)$, a significant effect of the brain region $(F(6,93)=3.70 ; p$ $=0.0024)$ and a significant dose $\mathrm{X}$ brain region interaction $(\mathrm{F}(12,93)=2.16 ; \mathrm{p}=0.02)$. Bonferroni post-hoc analysis showed that after 12 weeks exposure to $50 \mathrm{ppm}$ or $500 \mathrm{ppm}$ lead acetate there is a significant increase of lead content in all brain regions compared to vehicle group ( $\mathrm{p}$ values between $\mathrm{p}<0.01$ and $\mathrm{p}<0.0001$ ). In order to assess whether regionspecific differences in lead concentration correlate with the extent of the edema we performed linear regression analysis. No significant correlation was found between lead content and ADC increases $\left(\mathrm{R}^{2}=0.1532 ; \mathrm{p}=0.17\right)$ or between lead content and water content $\left(\mathrm{R}^{2}=0.2161 ; \mathrm{p}=0.09\right)$.

Blood lead concentration was significantly increased in lead exposed rats in a dosedependent manner: in control it was below limit of detection in 3 rats and mean $2 \pm 0.3$ $\mu \mathrm{g} / \mathrm{dL}$ in the other 3 rats, in the group of rats exposed to $50 \mathrm{ppm}$ blood lead concentration was were $12.3 \pm 2.2 \mu \mathrm{g} / \mathrm{dL}$ and in those exposed to $500 \mathrm{ppm}$ it was $55.4 \pm 8.6 \mu \mathrm{g} / \mathrm{dL}$. These lead concentrations are clinically relevant (Cory-Slechta, 1995; Kala and Jadhav, 1995).

\section{Discussion}

Magnetic resonance imaging (MRI) is the most important imaging modality to follow pathology non-invasively in the central nervous system since it allows to perform longitudinal studies and to access to anatomical information. The high spatial resolution of MRI can faithfully depict the state of pathology through different mechanisms. Diffusionweighted imaging measures the relative translational motion of water molecules across cell membrane, which is expressed by ADC. Changes in ADC can be due to brain oedema 
(Cauli et al. 2007 and 2010; Charles-Edwards and de Souza 2006; Gass et al., 2001; Schaefer 2000; Rovira et al. 2002).

Our results showed that chronic lead exposure in adult rats increased ADC value in different brain areas such as $\mathrm{CPu}$, Hip, $\mathrm{RF}, \mathrm{CC}$ and $\mathrm{Cb}$. However this effect was time- , dose- and brain region-dependent. Increases in ADC value were observed in 3 brain areas (Hip, RF and $\mathrm{Cb}$ ) after 4 weeks of 500 ppm lead exposure whereas exposure for 12 weeks of lead acetate modified $\mathrm{ADC}$ value in 5 brain regions (Hip, $\mathrm{RF}, \mathrm{Cb}, \mathrm{CPu}$ and $\mathrm{CC}$ ) in rats exposed to $500 \mathrm{ppm}$. Exposure to $50 \mathrm{ppm}$ lead acetate for 12 weeks increased ADC only in 2 brain regions ( $\mathrm{RF}$ and $\mathrm{Cb}$ ). In order to evaluate if $\mathrm{ADC}$ increases were due to cerebral oedema we measured water content at the end of longitudinal MRI studies. Those brain areas showing an increase of $\mathrm{ADC}$ also showed an increase of water content thus, confirming previous findings demonstrating that cerebral oedema can alter ADC value (Beaumont et al., 2000; Cauli et al. 2010; Kuroiwa et al., 1998). Exposure to 50 ppm increased $\mathrm{ADC}$ in $\mathrm{RF}$ and $\mathrm{Cb}$ but it did not significantly increase water content in these two brain areas although a trend was observed. Likely, sensitivity of ADC measurement to detect subtle changes in water diffusivity is greater than water content measurement by wet dry method. Interestingly, regions of cerebral cortex (MCx and SCx) showed no changes in ADC or in water content after lead exposure, an effect that was not related to a lower lead accumulation in these brain areas. In agreement with our findings, neonatal rats exposed to 4\% lead carbonate from postnatal day 12 until postnatal day 27 developed brain oedema in the cerebellum but not in the cerebral cortex (Hossain et al., 2004). One study performed by El-Neweshy et al. (2010) showed cerebellar oedema in rats chronically exposed to lead acetate for 60 days by daily intra-gastric administrations $(20 \mathrm{mg} / \mathrm{kg})$. In contrast to adult and 
newborn rats, prenatal exposure to lead (160 or 320 ppm of lead acetate solution during 21 days through drinking water) induced vasogenic oedema in brain fetuses in many brain regions including the parietal cortex (Villeda-Hernández et al., 2006) thus suggesting that mechanisms that modulate brain region susceptibility to lead are different between prenatal and postnatal period.

Those brain areas with increased ADC values displayed also an increase of Evans blue extravasation thus suggesting that increase of $\mathrm{BBB}$ permeability might play a role in the induction of vasogenic oedema.

The link between increase of ADC, vasogenic oedema and increased BBB permeability has been demonstrated in several pathologies of the CNS (Cauli et al., 2010; Chen et al., 2007; Kleindienst et al. 2006; Rother et al., 1996). Cerebellar oedema in newborn rats exposed to lead was accompanied by leakage of albumin across the BBB (Hossain et al., 2004). Increased BBB permeability has also been observed in weaning rats chronically exposed to lead for 6 weeks (342 ug Pb/mL) (Wang et al., 2007) or in newborn rats exposed to daily i.p. injections of lead nitrate $10 \mathrm{mg} / \mathrm{kg}$ body weight for the first 15 days of life (Sundstrom and Kalimo 1987; Sundstrom et al., 1985).

Struzynska et al., (1997) showed the BBB permeability to vascular proteins was increased in rats exposed to lead in the drinking water for 3 months. This effect was accompanied by neuropathological alterations of BBB such enhanced pinocytic activity of endothelial cells and the opening of tight junction, and increased phagocytosis of perycites (Struzynska et al., 1997). The relationship between vasogenic oedema and increase in BBB permeability is also supported by the fact that MCx and SCx show no alteration in ADC and no increase in BBB permeability. The reason why cerebral cortex is not sensitive to the increase of ADC 
value and BBB permeability induced by lead is unknown, future studies are needed to address this point.

Consequences of vasogenic edema during lead exposure might include an increase in intracranial pressure that in turn may lead to alterations of regional cerebral blood flow (Milhorat et al., 1989) with impairment of nutrients and oxygen supply to affected brain regions or impaired ability to maintain neuronal excitability (Amiry-Moghaddam and Ottersen 2003; Broberg et al., 2008).

\section{ACKNOWLEDGEMENTS}

This work was supported by the grant from the Ministerio de Ciencia y Innovación CTQ2009-14146-C02-02. 


\section{References}

Abe, K., Araki, T., Kogure, K., 1988. Recovery from oedema and of protein synthesis differs between the cortex and caudate following transient focal cerebral ischemia in rats. $\mathbf{J}$ Neurochem 51, 1470-1476.

Abraham, C.S., Deli, M.A., Joo, F., Megyeri, P., Torpier, G., 1996. Intracarotid tumor necrosis factor-alpha administration increases the blood-brain barrier permeability in cerebral cortex of the newborn pig: quantitative aspects of double-labelling studies and confocal laser scanning analysis. Neurosci Lett. 208(2), 85-8.

Amiry-Moghaddam, M, Ottersen, O.P., 2003. The molecular basis of water transport in the brain. Nat Rev Neurosci. 4(12), 991-1001.

Atre, A.L., Shindem, P.R., Shinde, S.N., Wadia, R.S., Nanivadekar, A.A., Vaid, S.J., Shinde, R.S., 2006. Pre- and posttreatment MR imaging findings in lead encephalopathy. AJNR Am J Neuroradiol. 27(4), 902-3

Beaumont, A., Marmarou, A., Hayasaki, K., Barzo, P., Fatouros, P., Corwin, F., Marmarou, C., Dunba,r J., 2000. The permissive nature of blood brain barrier (BBB) opening in oedema formation following traumatic brain injury. Acta Neurochir Suppl. 76, 125-9.

Broberg, M., Pope, K.J., Lewis, T., Olsson, T., Nilsson, M., Willoughby, J.O., 2008. Cell swelling precedes seizures induced by inhibition of astrocytic metabolism. Epilepsy Res. 80(2-3), 132-41.

Cauli, O., López-Larrubia, P., Rodrigo, R, Agusti, A., Boix, J., Nieto-Charques, L., Cerdán, S., Felipo, V., 2010. Brain Region-Selective Mechanisms Contribute to the Progression of Cerebral Alterations in Acute Liver Failure in Rats.Gastroenterology. Oct 23 in press. 
Cauli, O., López-Larrubia, P., Rodrigues, T.B., Cerdán, S., Felip,o V., 2007. Magnetic resonance analysis of the effects of acute ammonia intoxication on rat brain. Role of NMDA receptors. J Neurochem. 103(4), 1334-43.

CDC. Center for Disease Control and Prevention. 2000. Blood lead levels in young children-United States and selected states, 1996-1999. MMWR Morb Mortal Wkly Rep 49, 1133-1137.

Charles-Edwards, E.M., deSouza, N.M., 2006. Diffusion-weighted magnetic resonance imaging and its application to cancer. Cancer Imaging. 6, 135-43.

Chen, F., Suzuki, Y., Nagai, N., Jin, L., Yu, J., Wang, H., Marchal, G., Ni, Y., 2007. Rodent stroke induced by photochemical occlusion of proximal middle cerebral artery: evolution monitored with MR imaging and histopathology. Eur J Radiol. 63(1), 68-75.

Cory-Slechta, D.A., 1995. Bridging human and experimental animal studies of lead neurotoxicity: moving beyond IQ. Neurotoxicol Teratol. 17(3), 219-21.

Davis, I.M., Elias, R.W., Grant, L.D., 1993. Current issues in human lead exposure and regulation of lead. Neurotoxicology 14 (2-3), 15-28.

Friedheim, E., Corvi, C., Graziano, J., Donnelli, T., Breslin, D., 1983. Choroid plexus as a protective sink for heavy metals? Lancet. 1(8331), 981-2.

Gass, A., Niendorf, T., Hirsch, J.G., 2001. Acute and chronic changes of the apparent diffusion coefficient in neurological disorders--biophysical mechanisms and possible underlying histopathology. J Neurol Sci. 186 Suppl 1, S15-23.

Goldstein, G.W., Asbury, A.K., Diamond, I., 1974. Pathogenesis of lead encephalopathy. Uptake of lead and reaction of brain capillaries. Arch Neurol 31, 382-389.

Grandjean, P., 1993. International perspectives of lead exposure and lead toxicity. 
Neurotoxicol. 14, 9- 14

Fishman, R.A., 1975. Brain oedema. N Engl J Med 293(14), 706-711.

Hawkins, B.T., Davis, T.P., 2005. The blood-brain barrier/neurovascular unit in health and disease. Pharmacol Rev 57, 173-185.

Hawkins, B.T., Egleton, R.D., 2006 Fl.uorescence imaging of blood-brain barrier disruption. J Neurosci Methods 151, 262-267.

Holtzman, D., De Vries, C., Nguyen, H., Jameson, N., Olson, J., Carrithers, M., Bensch, K., 1982. Development of resistance to lead encephalopathy during maturation in the rat pup. J Neuropathol Exp Neurol. 41(6), 652-63.

Hossain, M.A., Russell, J.C., Miknyoczki, S., Ruggeri, B., Lal, B., Laterra, J., 2004. Vascular endothelial growth factor mediates vasogenic oedema in acute lead encephalopathy. Ann Neurol. 55(5), 660-7.

Kala, S.V., Jadhav, A.L., 1995. Low level lead exposure decreases in vivo release of dopamine in the rat nucleus accumbens: a microdialysis study. J Neurochem. 65(4), 1631-5. Klatzo, I., 1967. Neuropathological aspects of brain oedema. J Neuropathol Exp Neurol 26(1), 1-14.

Kleindienst, A., Dunbar, J.G., Glisson, R., Okuno, K., Marmarou, A., 2006. Effect of dimethyl sulfoxide on blood-brain barrier integrity following middle cerebral artery occlusion in the rat. Acta Neurochir Suppl. 96, 258-62.

Kuroiwa, T., Nagaoka, T., Ueki, M., Yamada, I., Miyasaka, N., Akimoto, H., 1998. Different apparent diffusion coefficient: water content correlations of gray and white matter during early ischemia. Stroke. 29(4), 859-65. 
Lefauconnier, J.M., Hauw. J.J., Bernard, G., 1983. Regressive or lethal lead encephalopathy in the suckling rat. Correlation of lead levels and morphological findings. $\mathbf{J}$ Neuropathol Exp Neurol. 42(2), 177-90.

Lögdberg, B., Brun, A., Berlin, M., Schütz, A., 1988. Congenital lead encephalopathy in monkeys. Acta Neuropathol. 77(2), 120-7.

Manton, W.I., Kirkpatrick, J.B., Cook, J.D., 1984. Does the choroid plexus really protect the brain from lead? Lancet. 2(8398), 351.

McManus, M.L., Churchwell, K.B., Strange, K., 1995. Regulation of cell volume in health and disease. N Engl J Med. 333(19), 1260-6.

Milhorat, T.H., Johnson, W.D., Dow-Edwards, D.L., 1989. Relationship between oedema, blood pressure, and blood flow following local brain injury. Neurol Res. 11(1), 29-32.

Paxinos, and Watson, C., 1996. The Rat Brain in Stereotaxic Coordinates., Academic Press, New York .

Pentschew, A., 1965. Morphology and morphogenesis of lead encephalopathy. Acta Neuropathol. 5, 133-160.

Rabinstein, A.A., 2006. Treatment of cerebral oedema. Neurologist. 12(2), 59-73.

Rojas-Marcos, I., Górriz, M., Santafosta, E., Coll, S., de Miquel, M.A., Serrallonga, M., Avila, J., 2002. Cerebellar ooedema and sideroblastic anaemia. Lancet. 360(9350), 2046.

Röther, J., Waggie, K., van Bruggen, N., de Crespigny, A.J., Moseley, M.E., 1996. Experimental cerebral venous thrombosis: evaluation using magnetic resonance imaging. J Cereb Blood Flow Metab. 16(6), 1353-61. 
Rovira, A., Córdoba, J., Raguer, N., Alonso, J., 2002. Magnetic resonance imaging measurement of brain oedema in patients with liver disease: resolution after transplantation. Curr Opin Neurol. 15(6), 731-7.

Saryan, L.A., Zenz, C., 1994. Lead and its compounds. In: Saryan LA, Zenz C, eds. Occupational Medicine. 3rd ed. St. Louis, Mo: Mosby 506-41.

Schaefer, P.W., 2000. Diffusion-weighted imaging as aproblem-solving tool in the evaluation of patients with acute strokelike syndromes. Top Magn Reson Imaging.11(5), 300-9.

Shaban, El-Neweshy, M.,Said, El-Sayed, Y., 2010. Influence of vitamin C supplementation on lead-induced histopathological alterations in male rats. Exp Toxicol Pathol. Jan 5. In press.

Shi, L.Z., Zheng, W., 2007. Early lead exposure increases the leakage of the bloodcerebrospinal fluid barrier, in vitro. Hum Exp Toxicol. 26(3), 159-67.

Sundström, R., Kalimo, H., 1987. Extracellular oedema and glial response to it in the cerebellum of suckling rats with low-dose lead encephalopathy. An electron microscopic and immunohistochemical study. Acta Neuropathol. 75(2), 116-22.

Sundström, R., Müntzing, K., Kalimo, H., Sourander, P., 1985. Changes in the integrity of the blood-brain barrier in suckling rats with low dose lead encephalopathy. Acta Neuropathol. 68(1), 1-9.

Struzyńska, L., Walski, M., Gadamski, R., Dabrowska-Bouta, B., Rafałowska, U., 1997. Lead-induced abnormalities in blood-brain barrier permeability in experimental chronic toxicity. Mol Chem Neuropathol. 31(3), 207-24. 
Toews, A.D., Kolber, A., Hayward, J., Krigman, M.R., Morell, P., 1978. Experimental lead encephalopathy in the suckling rat: concentration of lead in cellular fractions enriched in brain capillaries. Brain Res. 147(1), 131-8.

Villeda-Hernández, J., Méndez-Armenta, M., Barroso-Moguel, R., Trejo-Solis, M.C., Guevara, J., Rios, C., 2006. Morphometric analysis of brain lesions in rat fetuses prenatally exposed to low-level lead acetate: correlation with lipid peroxidation. Histol Histopathol. 21(6), 609-17.

Wang, Q., Luo, W., Zheng, W., Liu, Y., Xu, H., Zheng, G., Dai, Z., Zhang, W., Chen, Y., Chen, J., 2007. Iron supplement prevents lead-induced disruption of the blood-brain barrier during rat development. Toxicol Appl Pharmacol. 219(1), 33-41.

Winder, C., 1984. The Developmental Neurotoxicity of lead. MTP Press Ltd, Lancaster, Boston, the Hague, Dordrecht.

Zheng, W., Perry, D.F., Nelson, D.L., Aposhian, H.V., 1991. Choroid plexus protects cerebrospinal fluid against toxic metals. FASEB J. 5(8), 2188-93. 


\section{Legends to Figures}

Figure 1. ADC increase induced by chronic lead exposure.

Figures show representative images of ADC maps in the hippocampus (Hip) (images A-C indicated by two white arrows) and mesenchephalic reticular formation (RF) (images D-F indicated by the white arrow) after 12 weeks of lead acetate exposure via drinking water ( 0 , $50 \mathrm{ppm}$ or $500 \mathrm{ppm})$. As shown in the picture, change of ADC in Hip is observed only after exposure to $500 \mathrm{ppm}$ whereas hyperintensity of RF is observed after exposure to 50 and $500 \mathrm{ppm}$ (quantification of ADC values is shown in Table 3). Maps were quantified with Image $\mathbf{J}$ software as described in Material and Methods.

Figure 2. Water content in rats chronically treated with lead acetate.

After exposure to lead acetate $(0,50$ or $500 \mathrm{ppm})$ for 12 weeks in the drinking water rats were sacrified and water content was determined by wet dry method in each brain area as described in Material and Methods. Each values represent mean $\pm \mathrm{SEM}$ of $\mathrm{N}=6$ rats per group. * $\mathrm{p}<0.05 * * \mathrm{p}<0.01$ as compared to control group ( $0 \mathrm{ppm})$.

Figure 3. Blood brain barrier permeability in rats chronically treated with lead acetate.

After exposure to lead acetate $(0,50$ or $500 \mathrm{ppm})$ for 12 weeks in the drinking water rats received an iv. injection of Evans-Blue albumin complex and were sacrified one hour later as described in Material and Methods. Each values represent mean $\pm \mathrm{SEM}$ of $\mathrm{N}=6$ rats per group. $* \mathrm{p}<0.05 * * \mathrm{p}<0.01 * * * \mathrm{p}<0.001$ as compared to control group $(0 \mathrm{ppm})$. 
Figure 4. Lead content in different brain areas in rats chronically treated with lead acetate.

After exposure to lead acetate $(0,50$ or $500 \mathrm{ppm})$ for 12 weeks in the drinking water rats were sacrified and lead content was determined in each brain area as described in Material and Methods. Each values represent mean \pm SEM of $\mathrm{N}=6$ rats per group. ${ }^{*} \mathrm{p}<0.05 * * \mathrm{p}<$ $0.01 * * * \mathrm{p}<0.001$ as compared to control group $(0 \mathrm{ppm})$. 


\title{
Alterations of apparent diffusion coefficient (ADC) in the brain of rats chronically exposed to lead acetate.
}

\author{
Pilar López-Larrubia ${ }^{1}$ and Omar Cauli $^{2}$ \\ ${ }^{1}$ Laboratory for Imaging and Spectroscopy by Magnetic Resonance LISMAR, Instituto de \\ Investigaciones Biomédicas "Alberto Sols" C.S.I.C./UAM, Madrid, Spain \\ ${ }^{2}$ Laboratory of Neurobiology, Centro de Investigación Príncipe Felipe, Valencia, Spain
}

\begin{abstract}
Correspondence should be sent to: Dr. Omar Cauli, Laboratory of Neurobiology, Centro de Investigación Príncipe Felipe. Avda Autopista del Saler, 16, 46013 Valencia. e-mail: omar.cauli@cipf.es

Tel: $34963289680 \quad$ Fax: 34963289701
\end{abstract}

\begin{abstract}
ABBREVIATIONS:
ADC, apparent diffusion coefficient; BBB, blood-brain barrier; MRI, Magnetic resonance imaging; DWI, Diffusion-weighted imaging, $\mathrm{MCx}$, motor cortex; SCx, somato-sensory cortex; Hip, hippocampus; RF, reticular formation; $\mathrm{CC}$, corpus callosum; $\mathrm{CPu}$, caudateputamen; $\mathrm{Cb}$, cerebellum.
\end{abstract}




\section{ABSTRACT}

Diffusion-weighted imaging (DWI) allows the assessment of the water apparent diffusion coefficient (ADC), a measure of tissue water diffusivity which is altered during different pathological conditions such as cerebral oedema. By means of DWI, we repeatedly measured in the same rats apparent diffusion coefficient ADC in different brain areas (motor cortex $(\mathrm{MCx})$, somato-sensory cortex $(\mathrm{SCx})$, caudate-putamen $(\mathrm{CPu})$, hippocampus (Hip), mesencephalic reticular formation (RF), corpus callosum (CC) and cerebellum (Cb)) after 1 week, 4 and 12 weeks of lead acetate exposure via drinking water (50 or 500 ppm). After 12 weeks of lead exposure rats received albumin-Evans blue complex administration and were sacrified one hour later. Blood-brain barrier permeability and water tissue content were determined in order to evaluate their relationship with ADC changes. Chronic exposure to lead acetate (500 ppm) for 4 weeks increased ADC values in Hip, RF and $\mathrm{Cb}$ but no in other brain areas. After 12 weeks of lead acetate exposure at 500 ppm ADC is significantly increased also in $\mathrm{CPu}$ and $\mathrm{CC}$. Brain areas displaying high ADC values after lead exposure showed also an increased water content and increased BBB permeability to Evans blue-albumin complex. Exposure to 50 ppm for 12 weeks increased ADC values and $\mathrm{BBB}$ permeability in the RF and $\mathrm{Cb}$. In summary, chronic lead exposure induces cerebral oedema in the adult brain depending on the brain area and the dose of exposure. $\mathrm{RF}$ and $\mathrm{Cb}$ appeared the most sensitive brain areas whereas cerebral cortex appears resistant to leadinduced cerebral oedema.

KEY WORDS: lead neurotoxicity, vasogenic oedema, blood-brain barrier, reticular formation, apparent diffusion coefficient, magnetic resonance imaging 


\section{Introduction}

Lead $(\mathrm{Pb})$ neurotoxicity is still a major medical concern in both environmental and occupational settings (CDC 2000). The clinical effects of acute and chronic lead toxicity are well documented (Davis et al. 1993, Grandjean 1993). Acute lead intoxication induces oedema in the brain of humans and laboratory animals (Goldstein et al., 1974; Holtzman et al., 1982; Hossain et al., 2004; Lögdberg et al., 1988; Pentschew, 1965; Villeda-Hernández et al., 2006; Winder et al., 1983; Winder 1984 for review). Two main types of cerebral oedema have been described, namely, vasogenic and cytotoxic oedema. Vasogenic oedema can be induced when water entries into the brain following an alteration of blood-brain barrier (BBB) permeability thus leading to an accumulation of water in the extracellular space (Klatzo 1967). In cytotoxic oedema (also called cellular oedema), water accumulation occurs inside the cells mainly in astrocytes (Klatzo 1967).

It has been reported that acute lead intoxication in children and perinatal lead exposure in young animals cause cerebral oedema, in particular, vasogenic oedema (Hossain et al., 2004; Lefauconnier et al., 1983;Villeda-Hernández et al., 2006). Cytotoxic oedema has also been reported in one study (Lefauconnier et al., 1983). Different brain areas display different vulnerability to lead-induced cerebral oedema in young animals. Lead exposure (160 or $320 \mathrm{ppm}$ in the drinking water) from gestational day 1 to gestational day 21 dosedependently induce interstitial/vasogenic oedema in different brain regions of rat fetuses such as parietal cortex, striatum, thalamus and cerebellum (Villeda-Hernandez et al., 2006) while Hossain et al. (2004) reported that cerebellum is the more susceptible brain region to lead-induced oedema in newborn rats. One of the events that contribute to vasogenic 
oedema formation in the brain is the increase of BBB permeability.

Vasogenic oedema resulting from BBB failure causes transvascular leak of blood proteins (albumin, fibrinogen, fibronectin and immunoglobulins) with concurrent oncotic influx of water and failure of compensatory mechanisms of fluid homeostasis. According to the proposed link between alteration of $\mathrm{BBB}$ permeability and the occurrence of vasogenic oedema, it has been shown in young animals that lead exposure impairs BBB permeability (Hossain et al., 2004; Sundstrom and Kalimo 1987; Sundstrom et al., 1985; Wang et al., 2007).

Moreover, several reports have demonstrated that lead accumulates not only in BBB endothelial cells (Struzynska et al., 1997; Toews et al., 1978) but also in the choroid plexus (Friedheim et al., 1983; Manton et al., 1984; Zheng et al., 1991) where it increases the leakage of the blood-cerebrospinal fluid barrier (Shi and Zheng 2007). These findings suggest that the mechanisms involved in brain water homeostasis might be altered during lead exposure.

Magnetic resonance imaging (MRI) is a non invasive tool that provides information about changes in cerebral function in brain in vivo. MRI is the ideal modality to characterize the temporal and spatial evolutions of neuropathologies in vivo. Among different parameters that could be analyzed by MRI, diffusion weighted imaging (DWI) allows to calculate the apparent diffusion coefficient (ADC), which is altered in brain edema. ADC value reflects water mobility (expressed as $\mu \mathrm{m}^{2} / \mathrm{sec}$ ) in the tissue. Changes in ADC can reflect the presence of cerebral oedema (Rovira et al. 2002; Schaefer 2000) that, in turn, can be vasogenic or cytotoxic. Cytotoxic oedema is accompanied by a decrease of ADC value (Schaefer et al. 2000) while vasogenic oedema is accompanied by an increase of ADC 
value (McManus et al. 1995). In cytotoxic oedema ADC value decreases because water goes inside the cells where it cannot move as quickly as it can in the extracellular space. In vasogenic oedema, water content increases in the extracellular space leading to an increase of ADC value. Although children and youngest animals are more susceptible to leadinduced brain oedema (Holtzman et al., 1982; Winder 1984) it has also been reported in the adult brain following acute or subacute lead exposure (Atre et al., 2006; Rojas-Marcos I et al., 2002; Saryan and Zenz 1994). To our knowledge, no studies have been performed yet to address whether chronic lead exposure elicits brain oedema in the adult brain and if different brain areas present different susceptibility to this effect.

In this work we assessed:

1) whether chronic lead exposure $(0,50,500 \mathrm{ppm})$ in adults rats modifies ADC in different brain areas (motor cortex (MCx), somatosensory cortex (SCx), caudateputamen $(\mathrm{CPu})$, hippocampus (Hip), mesencephalic reticular formation $(\mathrm{RF})$, corpus callosum (CC) and cerebellum(Cb)).

2) the time-course of these changes by measuring ADC in the same subjects at different time points during lead exposure (1, 4 and 12 weeks).

3) If $\mathrm{ADC}$ alterations are accompanied by alterations of $\mathrm{BBB}$ permeability and water content.

Water content was measured by wet-dry method and BBB permeability by Evans-blue extravasation method which has been extensively used to study BBB permeability (Hawkins and Davis 2005 for review). 


\section{MATERIALS AND METHODS}

Male Wistar rats (250-300 g) were used. Rats were given food and water ad libitum and kept in the air-conditioned experimental room at $21-23{ }^{\circ} \mathrm{C}$ with a $12: 12 \mathrm{~h}$ light-dark cycle. Rats were divided into 3 groups: control rats drinking distillated water containing sodium acetate 50 or $500 \mathrm{ppm}(\mathrm{N}=3$ each); lead acetate $50 \mathrm{ppm}$ dissolved in the drinking water $(\mathrm{N}=6)$; lead acetate $500 \mathrm{ppm}$ dissolved in the drinking water $(\mathrm{N}=6)$. New solutions of lead acetate were prepared daily and acidified with chloridric acid (final $\mathrm{pH}$ 7) to avoid precipitation. The animal experiments were approved by the Center and met the guidelines of the European Community for care and management of experimental animals. Body weights were measured once per week and fluid intake every three days. After 12 weeks of lead exposure rats were injected with Evans blue (see below) and sacrificed one hour later. With the help of coronal slicer matrix (1 mm thickness slices) we isolated $\mathrm{MCx}, \mathrm{SCx}$, Hip, $\mathrm{CPu}$, half of the $\mathrm{Cb}$ (cut along the vermis), half of $\mathrm{CC}$ (cut perpendicular to the coronal plane), half of the mesenchephalic RF (cut coronally at the level of the fourth ventricle) from one hemisphere to measure the concentration of Evans blue and lead while the other brain areas belonging to the other hemisphere were used for water determination. Since the amount of tissue of $\mathrm{CC}$ is low, prior tissue processing, $3 \mathrm{CC}$ belonging to 3 different rats of the same experimental group were pooled together to measure Evans blue and lead. CC of remaining 3 rats were pooled together to determine water content. Data from control rats exposed to 50 or $500 \mathrm{ppm}$ of sodium acetate produced similar results in each of the measurements performed in the study so the data were pooled together.

\section{Magnetic Resonance Imaging (MRI) experiments}

MRI experiments were performed on a Bruker Pharmascan system (Bruker Medical Gmbh, 
Ettlingen, Germany) using a 7.0-T horizontal-bore superconducting magnet, equipped with a ${ }^{1} \mathrm{H}$ selective birdcage resonator of $38 \mathrm{~mm}$ and a Bruker gradient insert with $90 \mathrm{~mm}$ of diameter (maximum intensity $36 \mathrm{G} / \mathrm{cm}$ ). All data were acquired using a Hewlett-Packard console running Paravision software (Bruker Medical Gmbh, Ettlingen, Germany) operating on a Linux platform. Anesthesia was initiated by inhalation of oxygen (1 1/min) containing $4 \%$ isofluorane and maintained during the experiment employing a mask and 2 $\%$ isofluorane in $\mathrm{O}_{2}$. Animal temperature was maintained at approx. $37{ }^{\circ} \mathrm{C}$ with a heated probe. The physiological state of the rats was monitored using a Biotrig physiological monitor (Bruker, Germany) that controlled the respiratory rate and body temperature.

\section{Apparent diffusion coefficient (ADC) mapping}

Diffusion-weighted imaging (DWI) measures the relative translational motion of water molecules across cell membrane, which is expressed as the apparent diffusion coefficient (ADC) value.

The ADC maps were obtained based in diffusion weighted images and the following parameters: $\mathrm{TR}=2500 \mathrm{~ms}, \mathrm{TE}=25 \mathrm{~ms}, \mathrm{Av}=1$, diffusion gradient duration $=4 \mathrm{~ms}$, diffusion gradient separation $=16 \mathrm{~ms}$, acquisition matrix $=128 \times 128$ corresponding to an in-plane resolution of $312 \times 312 \mu \mathrm{m}^{2}$, b factors $=100,400$ and $1000 \mathrm{~s} / \mathrm{mm}^{2}$. Maps were obtained by a linear fitting of the logarithm of signal intensity (S) versus the $b$ factor according to the expression:

$$
\mathrm{S}_{\mathrm{b}}=\mathrm{S}_{0} \exp (-\mathrm{ADC} \times \mathrm{b})
$$

MRI signal intensity was analysed in the brain areas of interest by ADC values $\left(\mu \mathrm{m}^{2} / \mathrm{sec}\right)$ in the corresponding maps, after capturing images with Image $\mathbf{J}$ which calculates the mean value for all pixels contained in the selected brain region. The different brain regions were 
identified according to the stereotaxic coordinates of the rat brain atlas and to online plates of the atlas (Paxinos and Watson 1996). The regions analysed were $\mathrm{MCx}, \mathrm{SCx}, \mathrm{CPu}, \mathrm{Hip}$, $\mathrm{RF}, \mathrm{CC}$ and $\mathrm{Cb}$. ADC measurements were performed in the same subjects at different time points (1, 4 and 12 weeks) in order to perform a longitudinal study.

\section{Measurement of blood-brain barrier permeability}

BBB permeability was quantitatively evaluated by measuring the amount of extravasated Evans blue dye in the tissue at 12 weeks of chronic lead exposure according to procedure described in Hawkins and Egleton (2006). Evan's blue (2\%, containing 18 g/l bovine serum albumin $4 \mathrm{~mL} / \mathrm{kg}$ ) was injected over 2 min into the left femoral vein; it was allowed to circulate for $60 \mathrm{~min}$. After decapitation, the brain was removed and $\mathrm{MCx}, \mathrm{SCx}, \mathrm{CPu}$, Hip, $\mathrm{RF}, \mathrm{CC}$ and $\mathrm{Cb}$ were isolated. Brains areas were weighted and homogenized in five-fold volume of $50 \%$ trichloroacetic acid solution. The supernatant was obtained by centrifugation $\left(10 \mathrm{~min}, 10,000 \times g\right.$, at $\left.4{ }^{\circ} \mathrm{C}\right)$. Evans blue extravasation was quantified in the supernatants by measuring the fluorescence (excitation at $620 \mathrm{~nm}$ and emission at $680 \mathrm{~nm}$ ) (Abraham et al., 1996). The amount of extravasated Evans blue dye was expressed as nanogram per gram of brain tissue.

\section{Evaluation of brain oedema}

Wet-dry weight determinations (a simple and sensitive assay to measure brain oedema) of control and lead acetate-exposed brains were performed 12 weeks after chronic lead exposure. $\mathrm{MCx}, \mathrm{SCx}, \mathrm{CPu}$, Hip, $\mathrm{RF}, \mathrm{CC}$ and $\mathrm{Cb}$ were quickly dissected and the initial weight of each sample (wet weight) was determined. Samples then were dried in an oven at $110^{\circ} \mathrm{C}$ for 24 hours, and the respective dry weight for each specimen was obtained. Tissue water content was calculated as [(wet weight - dry weight)/wet weight $] \times 100 \%$ (Abe et 
al.1988).

\section{Lead measurement}

The day after the last MRI scanning, rats were anesthetized with isoflurane, rapidly decapitated, blood was collected from the neck and brain areas ( $\mathrm{MCx}, \mathrm{SCx}, \mathrm{CPu}, \mathrm{Hip}, \mathrm{RF}$, $\mathrm{CC}$ and $\mathrm{Cb}$ ) were immediately dissected, frozen on liquid nitrogen, and stored at $-80{ }^{\circ} \mathrm{C}$ until analysis of lead content. Lead content in brains and blood was analyzed by the Inductive Coupled Plasma-Atomic Emission Spectrometry (ICPAES). Brain tissue (20-40 mg) was first processed by wet digestion (20\% nitric acid and microwave exposure). The detection level of the method was $1.5 \mu \mathrm{g} / \mathrm{kg}$ wet-weight. For blood lead analysis, an aliquot of blood $(100 \mu \mathrm{l})$ were first diluted ten times with $0.1 \%$ triton X-100/nitric acid.

\section{Statistical analysis}

The results are presented as mean \pm standard error of mean (S.E.M.). The data were analyzed by one-way ANOVA followed Dunnett T-test or two-way ANOVA followed Bonferroni post-hoc test. $p$ values lower than 0.05 were considered statistically significant. Statistical analysis was performed using the Graph Pad Prism 5 software (GraphPad Software Inc. San Diego, CA, USA).

\section{RESULTS}

\section{Body weight, daily $\mathrm{Pb}$ fluid intake.}

No statistically differences in the gain of body weight of rats among the experimental

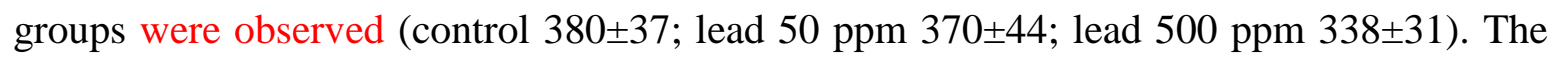
average daily intake of lead was 4.2 and $44 \mathrm{mg} \mathrm{Pb} / \mathrm{kg} /$ day for the group drinking water containing 50 and 500 ppm, respectively. No significant differences of fluid intake were observed among experimental groups. $\mathrm{Pb}$ intake in the control group (sodium acetate in the 
drinking water) was below the limit detection.

\section{Apparent diffusion coefficient}

$A D C$ values after one week of lead exposure

2-way analysis of variance of ADC values after one week of lead acetate exposure (50 or $500 \mathrm{ppm})$ shows no significant effect of dose $(\mathrm{F}(2,105)=0.097 ; \mathrm{p}=0.9903)$, a significant effect of the brain region $(\mathrm{F}(6,105)=140.6$; $\mathrm{p}<0.0001)$ and no significant dose $\mathrm{X}$ brain region interaction $(\mathrm{F}(12,105)=0.5524 ; \mathrm{p}=0.8750)$. The significant effect of brain region was due the lowest values of $\mathrm{ADC}$ in $\mathrm{CC}(\mathrm{p}<0.001)$, a pure white matter region. Each value is the mean of $\mathrm{N}=6$ rats. (Table 1 ).

$A D C$ values after four weeks of lead exposure

2-way analysis of variance of ADC values after four weeks of lead acetate exposure (50 or $500 \mathrm{ppm})$ shows a significant effect of dose $(\mathrm{F}(2,105)=6.70 ; \mathrm{P}<0.0018)$, a significant effect of the brain region $(\mathrm{F}(6,105)=167 ; \mathrm{p}<0.0001)$ and a significant dose $\mathrm{X}$ brain region interaction $(\mathrm{F}(12,105)=2.32 ; \mathrm{p}<0.0113)$. Bonferroni post-hoc test shows that exposure to lead acetate $500 \mathrm{ppm}$ in the drinking water significantly increased ADC value in Hip, RF and $\mathrm{Cb}(\mathrm{p}<0.05, \mathrm{p}<0.01, \mathrm{p}<0.05$ respectively) as compared to the ADC value of Hip, RF and $\mathrm{Cb}$ in the vehicle group. ADC values of $\mathrm{CC}$ were significantly lower as compared to ADC values of other brain regions but lead exposure did not significantly modify ADC value in CC. Exposure to $50 \mathrm{ppm}$ lead acetate did not produce any significant change of ADC values in any of the brain region examined (Table 2). Each value is the mean of $\mathrm{N}=6$ rats. 
$A D C$ values after twelve weeks of lead exposure

2-way analysis of variance of ADC values after twelve weeks of lead acetate exposure (50 or $500 \mathrm{ppm})$ shows a significant effect of dose $(\mathrm{F}(2,105=19.63 ; \mathrm{P}<0.0001)$, a significant effect of the brain region $(F(8,105)=170.2 ; \mathrm{p}<0.0001)$ and a significant dose $\mathrm{X}$ brain region interaction $(\mathrm{F}(12,105)=2.45 ; \mathrm{p}=0.0074)$. Bonferroni post-hoc test shows that exposure to lead acetate $50 \mathrm{ppm}$ in the drinking water significantly increased ADC value in $\mathrm{RF}(\mathrm{p}<0.05)$ and in $\mathrm{Cb}(\mathrm{p}<0.05)$ as compared to the $\mathrm{ADC}$ value of $\mathrm{RF}$ and of $\mathrm{Cb}$ in the vehicle group. Bonferroni post-hoc test shows that exposure to lead acetate $500 \mathrm{ppm}$ in the drinking water significantly increased $\mathrm{ADC}$ value in $\mathrm{CPu}(\mathrm{p}<0.01)$, Hip $(\mathrm{p}<0.05), \mathrm{RF}$ $(\mathrm{p}<0.01), \mathrm{CC}(\mathrm{p}<0.05)$ and $\mathrm{Cb}(\mathrm{p}<0.05)$ as compared to ADC values in the corresponding brain areas in the vehicle group. Moreover Bonferroni post-hoc test shows significant differences between $\mathrm{ADC}$ values of Hip, $\mathrm{CPu}$ and $\mathrm{CC}$ in rats exposed to $500 \mathrm{ppm}$ lead acetate compared to ADC values of $\mathrm{Hip}, \mathrm{CPu}$ and $\mathrm{CC}$ of rats exposed to $50 \mathrm{ppm} \quad(\mathrm{p}<0.05$ for Hip and $\mathrm{CC}$ and $\mathrm{p}<0.01$ for $\mathrm{CPu}$ ). Each value is the mean of $\mathrm{N}=6$ rats. (Table 3). Representative MRI scans showing ADC changes are reported in Figure 1.

\section{Determination of water content.}

In order to assess whether changes in ADC induced by lead exposure reflect the presence of cerebral oedema we determined water content (expressed as percentage of water in brain tissue) 12 weeks after lead acetate exposure (50 or $500 \mathrm{ppm}$ in the drinking water) in the same brain areas analyzed by MRI (Figure 2). 2-way analysis of variance of water content data shows a significant effect of dose $(F(2,93=13.94 ; \mathrm{p}<0.0001)$, a significant effect of the brain region $(\mathrm{F}(6,93)=3.03 ; \mathrm{p}<0.01)$ and a no significant dose $\mathrm{X}$ brain region interaction $(\mathrm{F}(12,93)=1.69 ; \mathrm{p}=0.08)$. Bonferroni post-hoc test shows that exposure to lead 
acetate at $500 \mathrm{ppm}$ in the drinking water significantly increased water content in $\mathrm{CPu}$ $(\mathrm{p}<0.05), \operatorname{Hip}(\mathrm{p}<0.01), \mathrm{RF}(\mathrm{p}<0.05), \mathrm{CC}(\mathrm{p}<0.01)$ and in $\mathrm{Cb}(\mathrm{p}<0.05)$ compared to water content in the corresponding brain areas in control rats. No significant differences were observed between water content in the group exposed to $50 \mathrm{ppm}$ lead acetate compared to vehicle group (Figure 2).

\section{Blood Brain Barrier permeability.}

In order to evaluate if ADC changes induced by chronic lead acetate (50 or $500 \mathrm{ppm}$ in the drinking water) were accompanied by alteration of $\mathrm{BBB}$ permeability we injected the fluorescent dye one hour before sacrifying the rats after 12 weeks of lead exposure. Evans blue was determined in the 7 brain areas and results expressed as $\mu \mathrm{g}$ of Evans blue/g tissue (Figure 3). 2-way analysis of variance of BBB permeability data shows a significant effect of dose $(F(2,93=39.44 ; p<0.0001)$, a significant effect of the brain region $(F(6,93)=6.21$; $\mathrm{p}<0.0001)$ and a significant dose $X$ brain region interaction $(F(12,93)=2.65 ; p=0.004)$. Bonferroni post-hoc test shows that exposure to lead acetate at $50 \mathrm{ppm}$ in the drinking water significantly increased BBB permeability in the RF $(\mathrm{p}<0.05)$, and in $\mathrm{Cb}(\mathrm{p}<0.05)$ compared to values of $\mathrm{RF}$ and $\mathrm{Cb}$ in control rats.

Bonferroni post-hoc test shows that exposure to $500 \mathrm{ppm}$ lead acetate in the drinking water significantly increased BBB permeability in $\mathrm{CPu}(\mathrm{p}<0.001), \operatorname{Hip}(\mathrm{p}<0.05), \mathrm{RF}(\mathrm{p}<0.01)$, $\mathrm{CC}(\mathrm{p}<0.05)$ and in $\mathrm{Cb}(\mathrm{p}<0.001)$ compared to the corresponding values in control rats.

\section{Lead levels in blood and in brain areas}

In order to assess whether results obtained for $\mathrm{ADC}$ values, water content and $\mathrm{BBB}$ permeability in different brain areas (MCx, SCx, $\mathrm{CPu}$, Hip, $\mathrm{RF}, \mathrm{CC}$ and $\mathrm{Cb}$ ) were due to different lead concentrations, we analyzed lead content in each brain area (expressed as 
$\mu \mathrm{g} / \mathrm{g}$ tissue) (Figure 4). Two-way analysis of variance shows a significant effect of dose (F $(2,93)=368.9 ; \mathrm{p}<0.0001)$, a significant effect of the brain region $(F(6,93)=3.70 ; \mathrm{p}$ $=0.0024)$ and a significant dose $\mathrm{X}$ brain region interaction $(\mathrm{F}(12,93)=2.16 ; \mathrm{p}=0.02)$. Bonferroni post-hoc analysis showed that after 12 weeks exposure to $50 \mathrm{ppm}$ or $500 \mathrm{ppm}$ lead acetate there is a significant increase of lead content in all brain regions compared to vehicle group ( $\mathrm{p}$ values between $\mathrm{p}<0.01$ and $\mathrm{p}<0.0001$ ). In order to assess whether regionspecific differences in lead concentration correlate with the extent of the edema we performed linear regression analysis. No significant correlation was found between lead content and ADC increases $\left(\mathrm{R}^{2}=0.1532 ; \mathrm{p}=0.17\right)$ or between lead content and water content $\left(\mathrm{R}^{2}=0.2161 ; \mathrm{p}=0.09\right)$.

Blood lead concentration was significantly increased in lead exposed rats in a dosedependent manner: in control it was below limit of detection in 3 rats and mean $2 \pm 0.3$ $\mu \mathrm{g} / \mathrm{dL}$ in the other 3 rats, in the group of rats exposed to $50 \mathrm{ppm}$ blood lead concentration was were $12.3 \pm 2.2 \mu \mathrm{g} / \mathrm{dL}$ and in those exposed to $500 \mathrm{ppm}$ it was $55.4 \pm 8.6 \mu \mathrm{g} / \mathrm{dL}$. These lead concentrations are clinically relevant (Cory-Slechta, 1995; Kala and Jadhav, 1995).

\section{Discussion}

Magnetic resonance imaging (MRI) is the most important imaging modality to follow pathology non-invasively in the central nervous system since it allows to perform longitudinal studies and to access to anatomical information. The high spatial resolution of MRI can faithfully depict the state of pathology through different mechanisms. Diffusionweighted imaging measures the relative translational motion of water molecules across cell membrane, which is expressed by ADC. Changes in ADC can be due to brain oedema 
(Cauli et al. 2007 and 2010; Charles-Edwards and de Souza 2006; Gass et al., 2001; Schaefer 2000; Rovira et al. 2002).

Our results showed that chronic lead exposure in adult rats increased ADC value in different brain areas such as $\mathrm{CPu}$, Hip, $\mathrm{RF}, \mathrm{CC}$ and $\mathrm{Cb}$. However this effect was time- , dose- and brain region-dependent. Increases in ADC value were observed in 3 brain areas (Hip, RF and $\mathrm{Cb}$ ) after 4 weeks of $500 \mathrm{ppm}$ lead exposure whereas exposure for 12 weeks of lead acetate modified $\mathrm{ADC}$ value in 5 brain regions (Hip, $\mathrm{RF}, \mathrm{Cb}, \mathrm{CPu}$ and $\mathrm{CC}$ ) in rats exposed to $500 \mathrm{ppm}$. Exposure to $50 \mathrm{ppm}$ lead acetate for 12 weeks increased ADC only in 2 brain regions ( $\mathrm{RF}$ and $\mathrm{Cb}$ ). In order to evaluate if $\mathrm{ADC}$ increases were due to cerebral oedema we measured water content at the end of longitudinal MRI studies. Those brain areas showing an increase of $\mathrm{ADC}$ also showed an increase of water content thus, confirming previous findings demonstrating that cerebral oedema can alter ADC value (Beaumont et al., 2000; Cauli et al. 2010; Kuroiwa et al., 1998). Exposure to $50 \mathrm{ppm}$ increased $\mathrm{ADC}$ in $\mathrm{RF}$ and $\mathrm{Cb}$ but it did not significantly increase water content in these two brain areas although a trend was observed. Likely, sensitivity of ADC measurement to detect subtle changes in water diffusivity is greater than water content measurement by wet dry method. Interestingly, regions of cerebral cortex (MCx and SCx) showed no changes in ADC or in water content after lead exposure, an effect that was not related to a lower lead accumulation in these brain areas. In agreement with our findings, neonatal rats exposed to 4\% lead carbonate from postnatal day 12 until postnatal day 27 developed brain oedema in the cerebellum but not in the cerebral cortex (Hossain et al., 2004). One study performed by El-Neweshy et al. (2010) showed cerebellar oedema in rats chronically exposed to lead acetate for 60 days by daily intra-gastric administrations $(20 \mathrm{mg} / \mathrm{kg})$. In contrast to adult and 
newborn rats, prenatal exposure to lead (160 or $320 \mathrm{ppm}$ of lead acetate solution during 21 days through drinking water) induced vasogenic oedema in brain fetuses in many brain regions including the parietal cortex (Villeda-Hernández et al., 2006) thus suggesting that mechanisms that modulate brain region susceptibility to lead are different between prenatal and postnatal period.

Those brain areas with increased ADC values displayed also an increase of Evans blue extravasation thus suggesting that increase of $\mathrm{BBB}$ permeability might play a role in the induction of vasogenic oedema.

The link between increase of ADC, vasogenic oedema and increased BBB permeability has been demonstrated in several pathologies of the CNS (Cauli et al., 2010; Chen et al., 2007; Kleindienst et al. 2006; Rother et al., 1996). Cerebellar oedema in newborn rats exposed to lead was accompanied by leakage of albumin across the BBB (Hossain et al., 2004). Increased BBB permeability has also been observed in weaning rats chronically exposed to lead for 6 weeks (342 ug Pb/mL) (Wang et al., 2007) or in newborn rats exposed to daily i.p. injections of lead nitrate $10 \mathrm{mg} / \mathrm{kg}$ body weight for the first 15 days of life (Sundstrom and Kalimo 1987; Sundstrom et al., 1985).

Struzynska et al., (1997) showed the BBB permeability to vascular proteins was increased in rats exposed to lead in the drinking water for 3 months. This effect was accompanied by neuropathological alterations of BBB such enhanced pinocytic activity of endothelial cells and the opening of tight junction, and increased phagocytosis of perycites (Struzynska et al., 1997). The relationship between vasogenic oedema and increase in BBB permeability is also supported by the fact that MCx and SCx show no alteration in ADC and no increase in BBB permeability. The reason why cerebral cortex is not sensitive to the increase of ADC 
value and $\mathrm{BBB}$ permeability induced by lead is unknown, future studies are needed to address this point.

Consequences of vasogenic edema during lead exposure might include an increase in intracranial pressure that in turn may lead to alterations of regional cerebral blood flow (Milhorat et al., 1989) with impairment of nutrients and oxygen supply to affected brain regions or impaired ability to maintain neuronal excitability (Amiry-Moghaddam and Ottersen 2003; Broberg et al., 2008).

\section{ACKNOWLEDGEMENTS}

This work was supported by the grant from the Ministerio de Ciencia y Innovación CTQ2009-14146-C02-02. 


\section{References}

Abe, K., Araki, T., Kogure, K., 1988. Recovery from oedema and of protein synthesis differs between the cortex and caudate following transient focal cerebral ischemia in rats. J Neurochem 51, 1470-1476.

Abraham, C.S., Deli, M.A., Joo, F., Megyeri, P., Torpier, G., 1996. Intracarotid tumor necrosis factor-alpha administration increases the blood-brain barrier permeability in cerebral cortex of the newborn pig: quantitative aspects of double-labelling studies and confocal laser scanning analysis. Neurosci Lett. 208(2), 85-8.

Amiry-Moghaddam, M, Ottersen, O.P., 2003. The molecular basis of water transport in the brain. Nat Rev Neurosci. 4(12), 991-1001.

Atre, A.L., Shindem, P.R., Shinde, S.N., Wadia, R.S., Nanivadekar, A.A., Vaid, S.J., Shinde, R.S., 2006. Pre- and posttreatment MR imaging findings in lead encephalopathy. AJNR Am J Neuroradiol. 27(4), 902-3

Beaumont, A., Marmarou, A., Hayasaki, K., Barzo, P., Fatouros, P., Corwin, F., Marmarou, C., Dunba,r J., 2000. The permissive nature of blood brain barrier (BBB) opening in oedema formation following traumatic brain injury. Acta Neurochir Suppl. 76, 125-9.

Broberg, M., Pope, K.J., Lewis, T., Olsson, T., Nilsson, M., Willoughby, J.O., 2008. Cell swelling precedes seizures induced by inhibition of astrocytic metabolism. Epilepsy Res. 80(2-3), 132-41.

Cauli, O., López-Larrubia, P., Rodrigo, R, Agusti, A., Boix, J., Nieto-Charques, L., Cerdán, S., Felipo, V., 2010. Brain Region-Selective Mechanisms Contribute to the Progression of Cerebral Alterations in Acute Liver Failure in Rats.Gastroenterology. Oct 23 in press. 
Cauli, O., López-Larrubia, P., Rodrigues, T.B., Cerdán, S., Felip,o V., 2007. Magnetic resonance analysis of the effects of acute ammonia intoxication on rat brain. Role of NMDA receptors. J Neurochem. 103(4), 1334-43.

CDC. Center for Disease Control and Prevention. 2000. Blood lead levels in young children-United States and selected states, 1996-1999. MMWR Morb Mortal Wkly Rep 49, 1133-1137.

Charles-Edwards, E.M., deSouza, N.M., 2006. Diffusion-weighted magnetic resonance imaging and its application to cancer. Cancer Imaging. 6, 135-43.

Chen, F., Suzuki, Y., Nagai, N., Jin, L., Yu, J., Wang, H., Marchal, G., Ni, Y., 2007. Rodent stroke induced by photochemical occlusion of proximal middle cerebral artery: evolution monitored with MR imaging and histopathology. Eur J Radiol. 63(1), 68-75.

Cory-Slechta, D.A., 1995. Bridging human and experimental animal studies of lead neurotoxicity: moving beyond IQ. Neurotoxicol Teratol. 17(3), 219-21.

Davis, I.M., Elias, R.W., Grant, L.D., 1993. Current issues in human lead exposure and regulation of lead. Neurotoxicology 14 (2-3), 15-28.

Friedheim, E., Corvi, C., Graziano, J., Donnelli, T., Breslin, D., 1983. Choroid plexus as a protective sink for heavy metals? Lancet. 1(8331), 981-2.

Gass, A., Niendorf, T., Hirsch, J.G., 2001. Acute and chronic changes of the apparent diffusion coefficient in neurological disorders--biophysical mechanisms and possible underlying histopathology. J Neurol Sci. 186 Suppl 1, S15-23.

Goldstein, G.W., Asbury, A.K., Diamond, I., 1974. Pathogenesis of lead encephalopathy. Uptake of lead and reaction of brain capillaries. Arch Neurol 31, 382-389.

Grandjean, P., 1993. International perspectives of lead exposure and lead toxicity. 
Neurotoxicol. 14, 9- 14

Fishman, R.A., 1975. Brain oedema. N Engl J Med 293(14), 706-711.

Hawkins, B.T., Davis, T.P., 2005. The blood-brain barrier/neurovascular unit in health and disease. Pharmacol Rev 57, 173-185.

Hawkins, B.T., Egleton, R.D., 2006 Fl.uorescence imaging of blood-brain barrier disruption. J Neurosci Methods 151, 262-267.

Holtzman, D., De Vries, C., Nguyen, H., Jameson, N., Olson, J., Carrithers, M., Bensch, K., 1982. Development of resistance to lead encephalopathy during maturation in the rat pup. J Neuropathol Exp Neurol. 41(6), 652-63.

Hossain, M.A., Russell, J.C., Miknyoczki, S., Ruggeri, B., Lal, B., Laterra, J., 2004. Vascular endothelial growth factor mediates vasogenic oedema in acute lead encephalopathy. Ann Neurol. 55(5), 660-7.

Kala, S.V., Jadhav, A.L., 1995. Low level lead exposure decreases in vivo release of dopamine in the rat nucleus accumbens: a microdialysis study. J Neurochem. 65(4), 1631-5. Klatzo, I., 1967. Neuropathological aspects of brain oedema. J Neuropathol Exp Neurol 26(1), 1-14.

Kleindienst, A., Dunbar, J.G., Glisson, R., Okuno, K., Marmarou, A., 2006. Effect of dimethyl sulfoxide on blood-brain barrier integrity following middle cerebral artery occlusion in the rat. Acta Neurochir Suppl. 96, 258-62.

Kuroiwa, T., Nagaoka, T., Ueki, M., Yamada, I., Miyasaka, N., Akimoto, H., 1998. Different apparent diffusion coefficient: water content correlations of gray and white matter during early ischemia. Stroke. 29(4), 859-65. 
Lefauconnier, J.M., Hauw. J.J., Bernard, G., 1983. Regressive or lethal lead encephalopathy in the suckling rat. Correlation of lead levels and morphological findings. $\mathbf{J}$ Neuropathol Exp Neurol. 42(2), 177-90.

Lögdberg, B., Brun, A., Berlin, M., Schütz, A., 1988. Congenital lead encephalopathy in monkeys. Acta Neuropathol. 77(2), 120-7.

Manton, W.I., Kirkpatrick, J.B., Cook, J.D., 1984. Does the choroid plexus really protect the brain from lead? Lancet. 2(8398), 351.

McManus, M.L., Churchwell, K.B., Strange, K., 1995. Regulation of cell volume in health and disease. N Engl J Med. 333(19), 1260-6.

Milhorat, T.H., Johnson, W.D., Dow-Edwards, D.L., 1989. Relationship between oedema, blood pressure, and blood flow following local brain injury. Neurol Res. 11(1), 29-32.

Paxinos, and Watson, C., 1996. The Rat Brain in Stereotaxic Coordinates., Academic Press, New York .

Pentschew, A., 1965. Morphology and morphogenesis of lead encephalopathy. Acta Neuropathol. 5, 133-160.

Rabinstein, A.A., 2006. Treatment of cerebral oedema. Neurologist. 12(2), 59-73.

Rojas-Marcos, I., Górriz, M., Santafosta, E., Coll, S., de Miquel, M.A., Serrallonga, M., Avila, J., 2002. Cerebellar ooedema and sideroblastic anaemia. Lancet. 360(9350), 2046.

Röther, J., Waggie, K., van Bruggen, N., de Crespigny, A.J., Moseley, M.E., 1996. Experimental cerebral venous thrombosis: evaluation using magnetic resonance imaging. J Cereb Blood Flow Metab. 16(6), 1353-61. 
Rovira, A., Córdoba, J., Raguer, N., Alonso, J., 2002. Magnetic resonance imaging measurement of brain oedema in patients with liver disease: resolution after transplantation. Curr Opin Neurol. 15(6), 731-7.

Saryan, L.A., Zenz, C., 1994. Lead and its compounds. In: Saryan LA, Zenz C, eds. Occupational Medicine. 3rd ed. St. Louis, Mo: Mosby 506-41.

Schaefer, P.W., 2000. Diffusion-weighted imaging as aproblem-solving tool in the evaluation of patients with acute strokelike syndromes. Top Magn Reson Imaging.11(5), 300-9.

Shaban, El-Neweshy, M.,Said, El-Sayed, Y., 2010. Influence of vitamin C supplementation on lead-induced histopathological alterations in male rats. Exp Toxicol Pathol. Jan 5. In press.

Shi, L.Z., Zheng, W., 2007. Early lead exposure increases the leakage of the bloodcerebrospinal fluid barrier, in vitro. Hum Exp Toxicol. 26(3), 159-67.

Sundström, R., Kalimo, H., 1987. Extracellular oedema and glial response to it in the cerebellum of suckling rats with low-dose lead encephalopathy. An electron microscopic and immunohistochemical study. Acta Neuropathol. 75(2), 116-22.

Sundström, R., Müntzing, K., Kalimo, H., Sourander, P., 1985. Changes in the integrity of the blood-brain barrier in suckling rats with low dose lead encephalopathy. Acta Neuropathol. 68(1), 1-9.

Struzyńska, L., Walski, M., Gadamski, R., Dabrowska-Bouta, B., Rafałowska, U., 1997. Lead-induced abnormalities in blood-brain barrier permeability in experimental chronic toxicity. Mol Chem Neuropathol. 31(3), 207-24. 
Toews, A.D., Kolber, A., Hayward, J., Krigman, M.R., Morell, P., 1978. Experimental lead encephalopathy in the suckling rat: concentration of lead in cellular fractions enriched in brain capillaries. Brain Res. 147(1), 131-8.

Villeda-Hernández, J., Méndez-Armenta, M., Barroso-Moguel, R., Trejo-Solis, M.C., Guevara, J., Rios, C., 2006. Morphometric analysis of brain lesions in rat fetuses prenatally exposed to low-level lead acetate: correlation with lipid peroxidation. Histol Histopathol. 21(6), 609-17.

Wang, Q., Luo, W., Zheng, W., Liu, Y., Xu, H., Zheng, G., Dai, Z., Zhang, W., Chen, Y., Chen, J., 2007. Iron supplement prevents lead-induced disruption of the blood-brain barrier during rat development. Toxicol Appl Pharmacol. 219(1), 33-41.

Winder, C., 1984. The Developmental Neurotoxicity of lead. MTP Press Ltd, Lancaster, Boston, the Hague, Dordrecht.

Zheng, W., Perry, D.F., Nelson, D.L., Aposhian, H.V., 1991. Choroid plexus protects cerebrospinal fluid against toxic metals. FASEB J. 5(8), 2188-93. 


\section{Legends to Figures}

Figure 1. ADC increase induced by chronic lead exposure.

Figures show representative images of ADC maps in the hippocampus (Hip) (images A-C indicated by two white arrows) and mesenchephalic reticular formation (RF) (images D-F indicated by the white arrow) after 12 weeks of lead acetate exposure via drinking water ( 0 , $50 \mathrm{ppm}$ or $500 \mathrm{ppm})$. As shown in the picture, change of ADC in Hip is observed only after exposure to $500 \mathrm{ppm}$ whereas hyperintensity of RF is observed after exposure to 50 and $500 \mathrm{ppm}$ (quantification of ADC values is shown in Table 3). Maps were quantified with Image $\mathbf{J}$ software as described in Material and Methods.

Figure 2. Water content in rats chronically treated with lead acetate.

After exposure to lead acetate $(0,50$ or $500 \mathrm{ppm})$ for 12 weeks in the drinking water rats were sacrified and water content was determined by wet dry method in each brain area as described in Material and Methods. Each values represent mean $\pm \mathrm{SEM}$ of $\mathrm{N}=6$ rats per group. $* \mathrm{p}<0.05 * * \mathrm{p}<0.01$ as compared to control group (0 ppm).

\section{Figure 3. Blood brain barrier permeability in rats chronically treated with lead acetate.}

After exposure to lead acetate $(0,50$ or $500 \mathrm{ppm})$ for 12 weeks in the drinking water rats received an iv. injection of Evans-Blue albumin complex and were sacrified one hour later as described in Material and Methods. Each values represent mean $\pm \mathrm{SEM}$ of $\mathrm{N}=6$ rats per group. $* \mathrm{p}<0.05 * * \mathrm{p}<0.01 * * * \mathrm{p}<0.001$ as compared to control group $(0 \mathrm{ppm})$ 
Figure 4. Lead content in different brain areas in rats chronically treated with lead acetate.

After exposure to lead acetate $(0,50$ or $500 \mathrm{ppm})$ for 12 weeks in the drinking water rats were sacrified and lead content was determined in each brain area as described in Material and Methods. Each values represent mean \pm SEM of $\mathrm{N}=6$ rats per group. $* \mathrm{p}<0.05 * * \mathrm{p}<$ $0.01 * * * \mathrm{p}<0.001$ as compared to control group $(0 \mathrm{ppm})$. 
Table 1. ADC values $\left(x 10^{(-1)} \mu \mathrm{m}^{2} / \mathrm{sec}\right)$ in different brain areas after lead acetate exposure $(0,50,500 \mathrm{ppm})$ in the drinking water for 1 week.

\begin{tabular}{|l|l|l|l|}
\hline Brain area & 0 ppm & 50 ppm & 500 pm \\
\hline MCx & & & \\
\hline SCx & $8465 \pm 194$ & $8235 \pm 124$ & $8350 \pm 139$ \\
\hline CPu & $8322 \pm 155$ & $8197 \pm 194$ & $8108 \pm 201$ \\
\hline Hip & $8104 \pm 165$ & $8216 \pm 138$ & $8378 \pm 188$ \\
\hline RF & $9245 \pm 170$ & $9326 \pm 186$ & $9384 \pm 189$ \\
\hline CC & $9985 \pm 114$ & $9816 \pm 174$ & $10064 \pm 182$ \\
\hline Cb & $7002 \pm 120$ & $7147 \pm 105$ & $6958 \pm 108$ \\
\hline
\end{tabular}

Rats were exposed via the drinking water to sodium acetate $(0 \mathrm{ppm})$, or one of the concentrations of lead acetate (50 ppm or $500 \mathrm{ppm})$. 1 week after exposure they were anaesthetized and subjected to MRI as described in Methods. ADC values were calculated in the following brain regions: motor cortex $(\mathrm{MCx})$, somato-sensory cortex (SCx), caudate-putamen ( $\mathrm{Cpu}$ ), hippocampus (Hip), mesencephalic reticular formation (RF), corpus callosum (CC) and cerebellum (Cb). Values are the mean \pm SEM of six rats per group. Values that are significantly different from control are indicated by asterisks $* \mathrm{p}<0.05$ 
Table 2. ADC values $\left(x 10^{(-1)} \mu \mathrm{m}^{2} / \mathrm{sec}\right)$ in different brain areas after lead acetate exposure $(0,50,500 \mathrm{ppm})$ in the drinking water for 4 weeks.

\begin{tabular}{|l|l|l|l|}
\hline Brain area & 0 ppm & 50 ppm & 500 ppm \\
\hline MCx & & & \\
\hline SCx & $8542 \pm 150$ & $8281 \pm 156$ & $8493 \pm 185$ \\
\hline CPu & $8245 \pm 147$ & $8188 \pm 171$ & $8145 \pm 178$ \\
\hline Hip & $8004 \pm 202$ & $8048 \pm 156$ & $8207 \pm 252$ \\
\hline RF & $9499 \pm 126$ & $9584 \pm 133$ & $9962 \pm 154 *$ \\
\hline CC & $10042 \pm 145$ & $10016 \pm 198$ & $10454 \pm 177 * *$ \\
\hline Cb & $7058 \pm 84$ & $7120 \pm 111$ & $7156 \pm 105$ \\
\hline
\end{tabular}

Rats were exposed via the drinking water sodium acetate $(0 \mathrm{ppm})$, or one of the concentrations of lead acetate (50 ppm or 500 ppm). 4 weeks ( \pm 3 days) after exposure there were anaesthetized and subjected to MRI as described in Methods. ADC values were calculated in the following brain regions: motor cortex (MCx), somato-sensory cortex (SCx), caudate-putamen (Cpu), hippocampus (Hip), mesencephalic reticular formation $(\mathrm{RF})$, corpus callosum $(\mathrm{CC})$ and cerebellum $(\mathrm{Cb})$. Values are the mean \pm SEM of six rats per group. Values that are significantly different from control are indicated by asterisks $* \mathrm{p}<0.05 ; * * \mathrm{p}<0.01$. 
Table 3. ADC values $\left(x-10^{(-1)} \mu \mathrm{m}^{2} / \mathrm{sec}\right)$ in different brain areas after lead acetate exposure $(0,50,500 \mathrm{ppm})$ in the drinking water for 12 weeks.

\begin{tabular}{|l|l|l|l|}
\hline Brain area & 0 ppm & $50 \mathrm{ppm}$ & $500 \mathrm{pm}$ \\
\hline MCx & & & \\
\hline SCx & $8377 \pm 165$ & $8240 \pm 131$ & $8403 \pm 154$ \\
\hline CPu & $8305 \pm 158$ & $8285 \pm 186$ & $8461 \pm 150$ \\
\hline Hip & $8155 \pm 173$ & $8289 \pm 171$ & $8502 \pm 206 *$ \\
\hline RF & $9256 \pm 138$ & $9156 \pm 165$ & $9874 \pm 117 *$ \\
\hline CC & $10125 \pm 178$ & $10565 \pm 164 *$ & $11065 \pm 191 * *$ \\
\hline Cb & $7247 \pm 97$ & $7356 \pm 131$ & $7655 \pm 127 *$ \\
\hline
\end{tabular}

Rats were exposed via the drinking water sodium acetate $(0 \mathrm{ppm})$, or one of the concentrations of lead acetate (50 ppm or 500 ppm). 10 weeks ( \pm 4 days) after exposure there were anaesthetized and subjected to MRI as described in Methods. ADC values were calculated in the following brain regions motor cortex (MCx), somato-sensory cortex (SCx), caudate-putamen $(\mathrm{Cpu})$, hippocampus (Hip), mesencephalic reticular formation $(\mathrm{RF})$, corpus callosum $(\mathrm{CC})$ and cerebellum $(\mathrm{Cb})$. Values are the mean \pm SEM of six rats per group. Values that are significantly different from control are indicated by asterisks $* \mathrm{p}<0.05$. 
Click here to download high resolution image
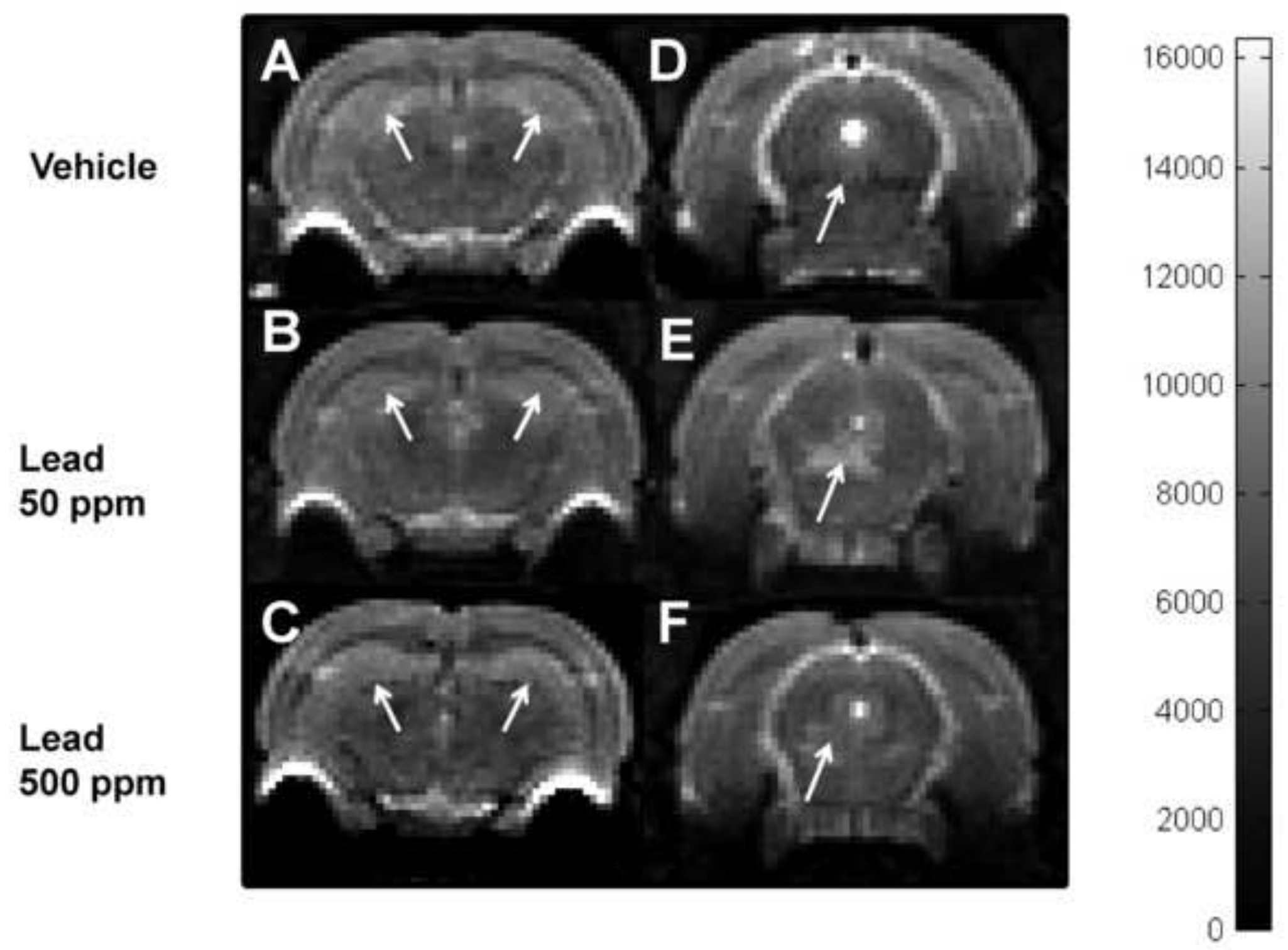


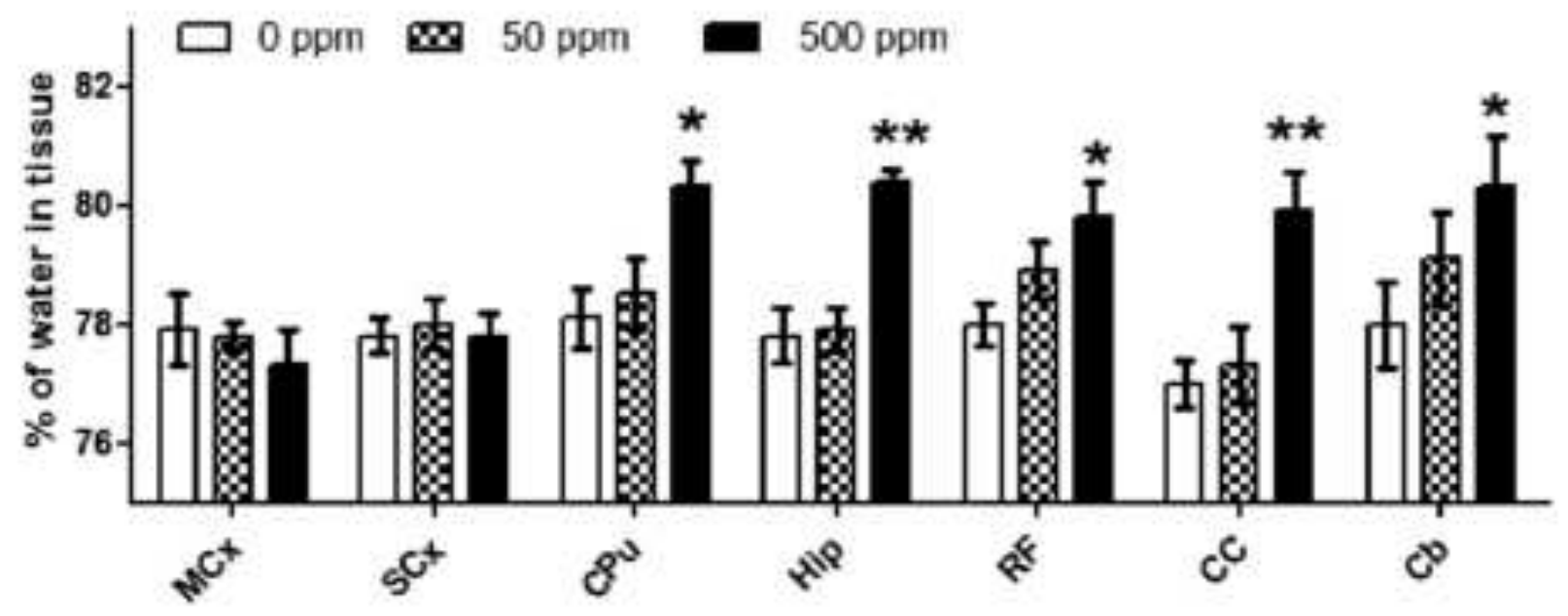

Figure 2 


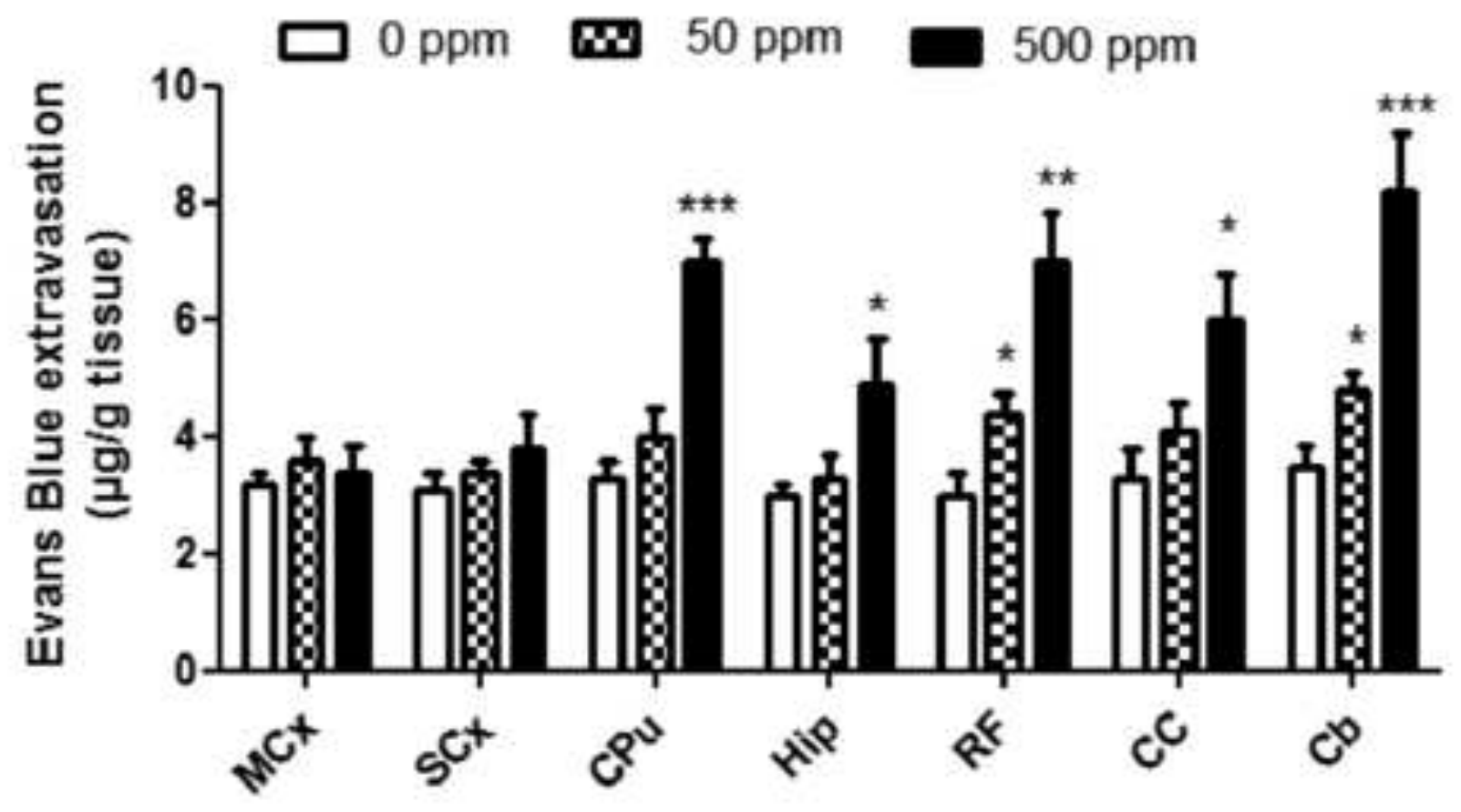

Figure 3 


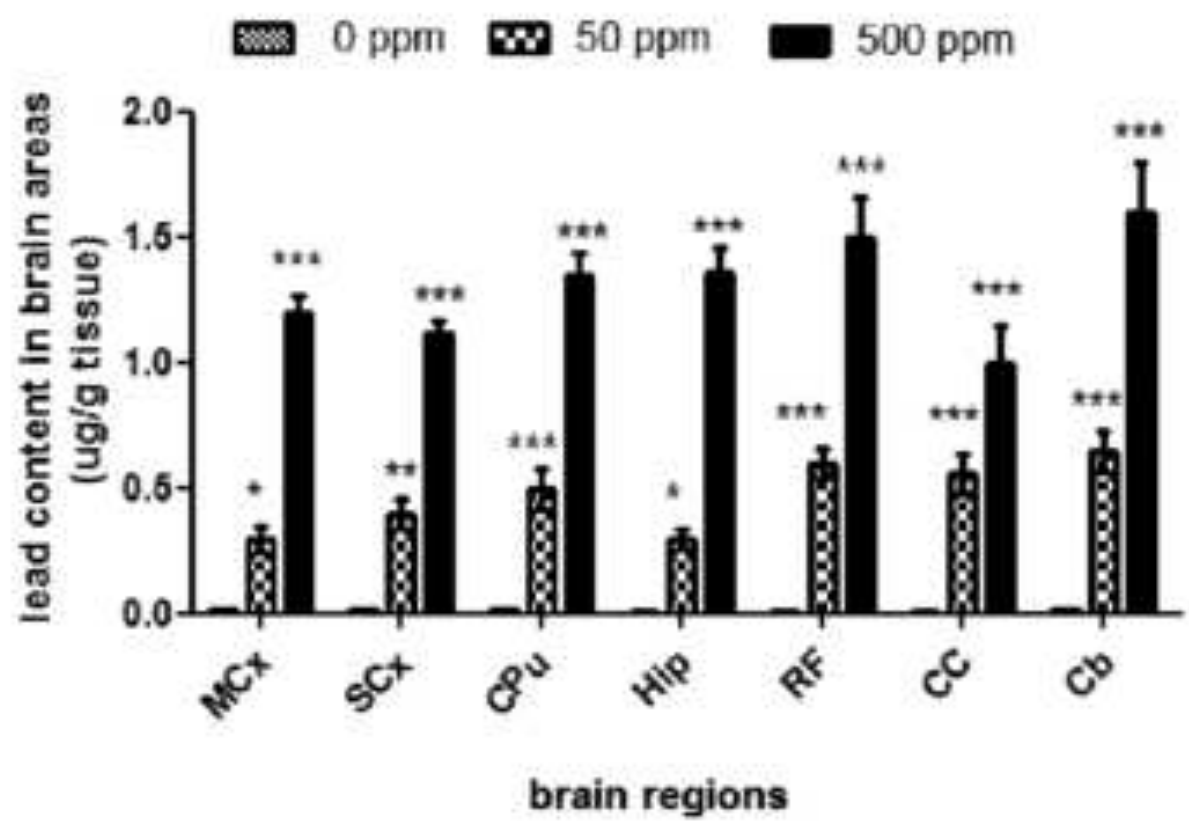

Figure 4 
$11^{\text {th }}$ december 2010

To the Editor of journal "Toxicology".

\section{Conflict of Interest statement:}

The authors declare that there are no conflicts of interest relative to article submitted to the journal entitled: "Alterations of apparent diffusion coefficient (ADC) in the brain of rats chronically exposed to lead acetate."

by Pilar López-Larrubia ${ }^{1}$ and Omar Cauli ${ }^{2}$

${ }^{1}$ Laboratory for Imaging and Spectroscopy by Magnetic Resonance LISMAR, Instituto de Investigaciones Biomédicas "Alberto Sols" C.S.I.C./UAM, Madrid, Spain

${ }^{2}$ Laboratory of Neurobiology, Centro de Investigación Príncipe Felipe, Valencia, Spain 